\title{
THE FAR INFRARED SPECTRA OF SEVERAL PYRAMIDAL TRIHALIDES
}

\author{
DISSERTATION \\ Fresented in Fartial Fulfillment of the Requirements \\ for the Degree Doctor of Philosophy in the \\ Graduate School of The Ohio State \\ University
}

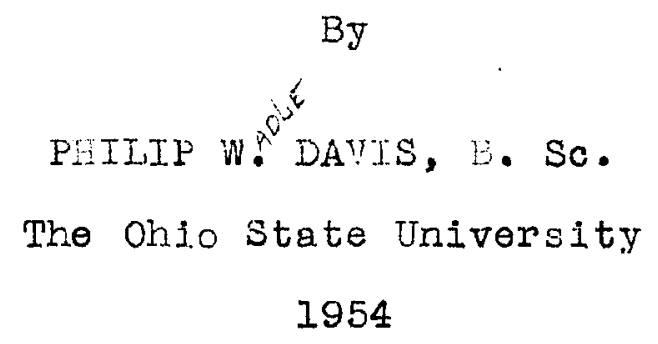

Approved by:

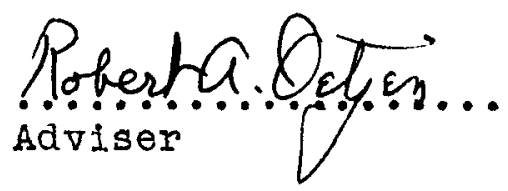




\section{ACKNOWLEDGEMENT}

I should like to express my appreciation to Dr. Robert A. Oetjen and to Dr. Ely E. Bebl for their gridance and patience during the course of this work. The everpresent aid of the indefatigable Raymond L. Brown and Edward D. Palik of this laboratory was of great assistance to me throughout the time the work was in progress.

I am indebted to The Onio State University Research Foundation for allowing me a Fellowship for the year 195253 and to the Wright Air Development Center for permitting me to use the far infrared spectrometer to carry out thio investigation.

Finally the excellent work of $\mathrm{Mr}$. Carl MoWhirt and the staff of the Physics Department shop is gratefully acknowled ged. 
TABLE OF CONTENTS

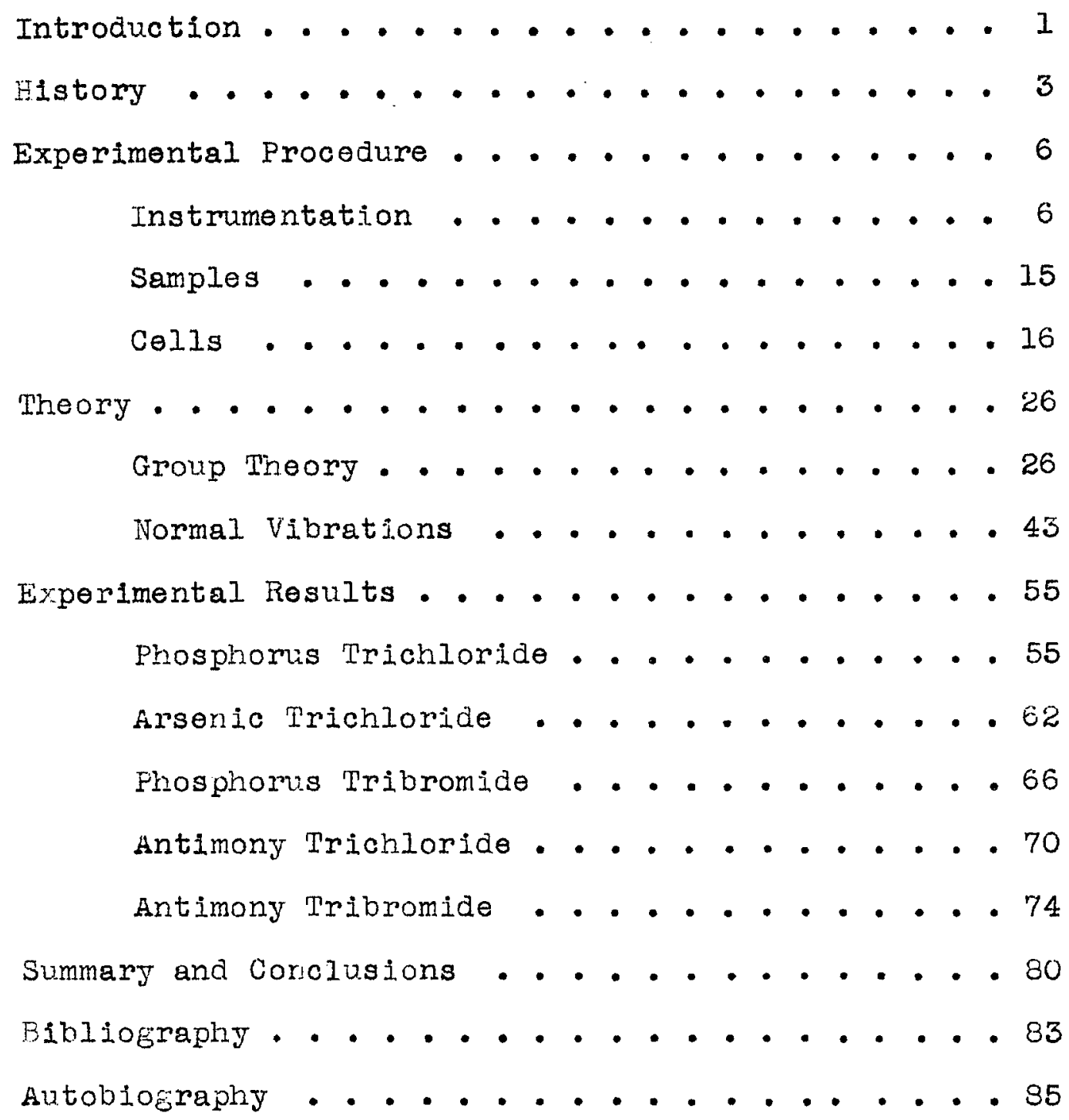




\section{INRRODUCTION}

The trihalides of the fifth group of elements of the periodic table are of the $\mathrm{XY}_{3}$ pyramidal type, the base of the pyramld being formed of the three halogen utoms arranged as an equilateral triangle and the apex of the pyramid being an atom of nitrogen*, phosphorus, arsenic, antimony or bismuth. For this type of molecule there are four aistinct vibrational fundamental frequencies, and for the halogens having mass greater than that of fluorine and with the peak atom of the mass of phosphorus or greater, all of these frequencies will lie at wavelengths longer than 20 microns.

The five molecules treated in this investigation are phosphorus trichloride, phosphorus tribromide, antimony trichloride, antimony tribromide und arsenic trichloride. of these five molecules, four have been previously studied by means of Raman spectroscopy, the exception boing SbBr. The only infrared investigation ras the examination of the $189 \mathrm{~cm}^{-1}$ vibration of $\mathrm{PCl}_{3}$ by Oloune (1) who used reststrahlen techniques. Several of the lichter molecules of this fumily have been studied in recent years ( 2 ) (o), their fundamental frequencies falling into the wave lencth resion shorter than 25 microns. Some of the analytic methods used

\footnotetext{
* The nitrogen compounds tend to be explosive.

(I) J. O'Loane, J. Chem. Phys., ¿2I, 669 (1953)

(2) W. K. Wilson, J. Chom. Phys., zO, 1716 (1952)

(s) H. Gatowsky, J. Chem. Phys. 20, 165\% (1952)
} 
in interpreting these spectra are also employed in this stondy. The recent acquisition of a reflection grating ruled with 550 Iines per inch made possible the extension of the range of The Ohio State University far infrared spectrometer so that it can be used between 20 and 140 microns; this fact, coupled with some modifications of the instrument which permitted liquid und solid samples to be rather easily introduced into the light path made it possible to measure the far infrared spectra of these substances. 


\section{HISTORY}

The trihalides of the nitrogen column of the periodic table are pyramidal in shape (point group $C_{s v}$ ) and are thus similar to ammonia, phosphine and arsine in their gross spectral features. The pyramidal $X Y_{3}$ type of molecule is the simplest nonlinear, nonplanar molecule and has thus boen well investigated both experimentally and theoretically during the past threo decades. In addition to the literature which deals with the pure rotational spectra of $X Y_{5}$ symmetric top molecules there exists a large body of papers dealing with their vibrational frequencies. Dennison (4) and Lechner (5) did early theoretical work on the $\mathrm{XY}_{5}$ normal mode problem and attempted a comparison with the then known ammonia vibration bands. Iloward and Wilson (6) approached the problem using a rather more accurate potential function while Rosenthul (7) worked it out usine the most generul harmonic potential function consistent with the symetry of the molecule; namely a six constant runction, but one wherein the six constants were not easily visualizod in terms of directIy apparent physical forces in the molecule such as those ussociated with bending and stretching.

(4) D. M. Dennison, philosophical Magazine, I, 195 (1926)

(5) F. Lechner, wiener Ber. 141, 663 (1932)

(6) J. Howard and E. Wilson, J. Chem. Phys. $\underline{\text { J }}, 630$ (1934)

(7) J. Rosenthal, Fhys. Rev. 47, 235 (1935) 
The question of interaction between the rotation and internal ansular momentur was attacked piecemeal by several investigators and has been treated comprehensively by Shaffer (8) who applied the quantum mechanical perturbation theory to account for anharmonicities and vibration-rotation interaction. Recently there has been another flurry of theoretical activity, mainly concerned with analysis of the pyramidal hydrides of the nitrogen group of the periodic table. In the present report the treatment will follow that of Howard and wilson for the most part.

It can be shown quite simply from group theory that molecules of this structure have all of their vibrutional fundamentals both infrared and Raman active (10); consequently there was a consicierabje number of Raman spectre obtalnod from these molecvies, especially durine the early years of that branch of spectroscopy. Reports of these Raman investigations ure listed by Kohlrausch (II) and Horzberg (12) and wor liberally used in this undertaking, both as guides to approximate line locations and as aids in assignment. Erockway (13) made an electron diffraction study of

\footnotetext{
(8) W. H. Shaffer, d. Chem. Poys. 9, 607 (154I)

(9) I. Burrelle, J. Chem. Phys. 18, 1300 (1950)

(10) J. Walter, H. Eyring, and G. Fimball, Quantum Chemistry, Now York, 1944

(II) K. W. F. Kohlrausch, Der Sraekal-Raman-Effekt, Ergdnzungsband, 1931-1937, Berin, 1938 .

(Ii) G. Herzberg, Molecular Spectru and Nolecular Structure II Infrared and Raman Spectru of Polyutomic roleculos, New YIrk, 1945 .

(13) L. 0. Prockway, Rev. Mod. Phys. 8, 231 (1936)
} 
several of these molecules, obtaining bond distances and angles. Recently very accurate values of the bond angles have been obtained from microwave measurements reported by Gordy and coworkers (14). The angles used in the treatment of the data obtained in the present investigation are taken from these microwave results except for SbBr.s for which Brockway's electron diffraction data are the best available.

(14) W. Gordy, W. Smith, and R. Trambarulo, Microwave Spectroscopy, New York, 1953. 


\section{EXPERIMENTAL PROCEDUEE}

\section{Instmumentation}

The spectrograph used for obtaining the data is that constructed at The Ohio State university (15). In the two years since it was previously described, however, some changes in design ave be made which bear reporting in some detail.

It was sugjested by professor Hily $E$. Bell of this laboratory that the cause of a plague of instability troubles in the signal output might lie in the fact that the Golay detector was supported in such a fashion as to be within the evacuated portion of the spectrograph when data were being taken. As a resilt, if the fus chamber of the detector leaked at ull the pressure of the working gas in the detector (usually xenon) might eventually drop sufficiently to change the sensitivity. To correct this, the arrangement shown in Figure 1 was designed and constructed.

This scheme leaves the detector in the atmosphere with, however, only a centimeter path length for the radiation in the open air. The one or two oi the strongest water vapor lines remaining in the spectrum (as a result of

(15) R. A. Oetjen, W. H. Ilaynie, W. M. Ward, R. I. Ilansler, H. E. Schauwecher and E. E. Bell, J.0.B.A. 42,559 (I952) 


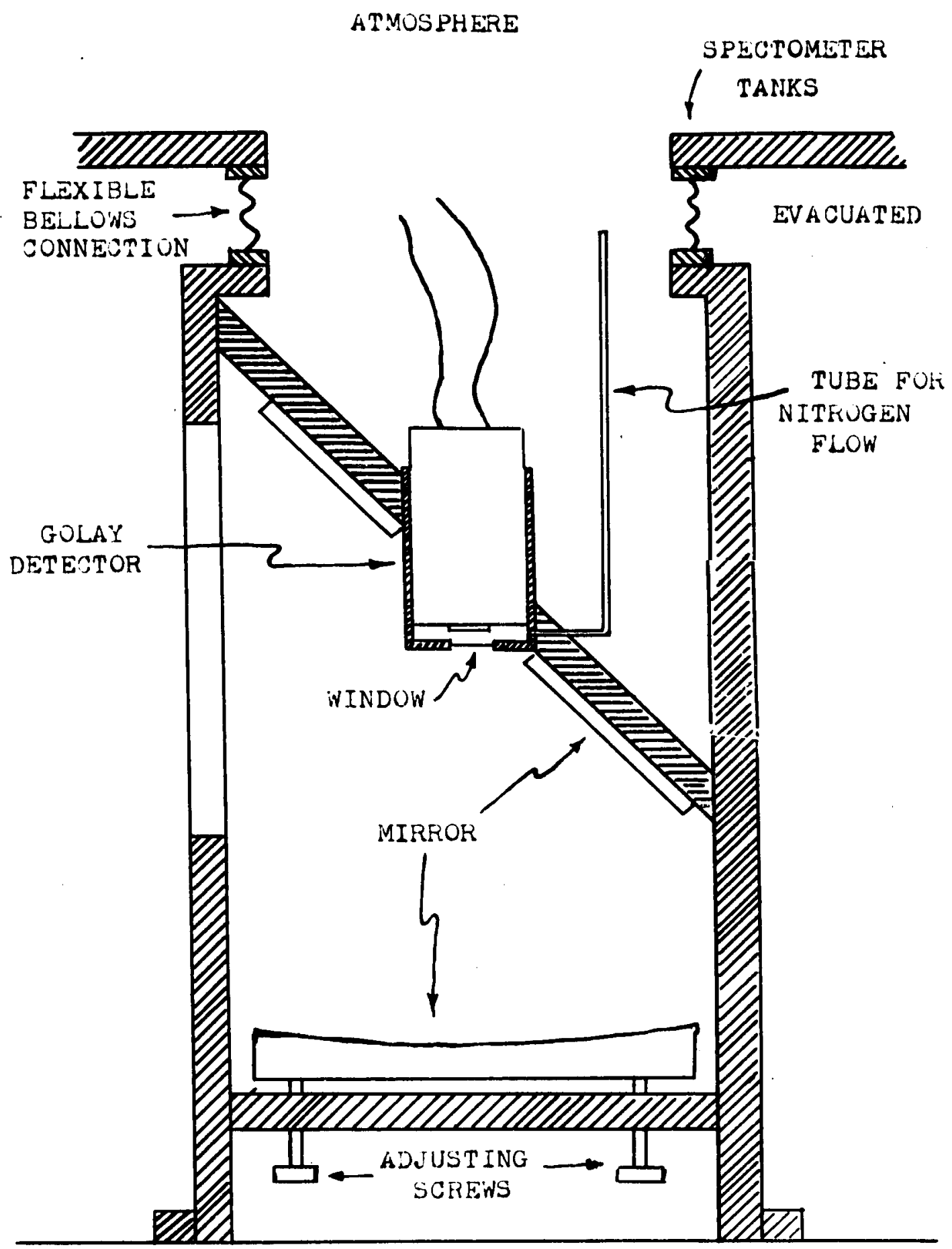

DETEOTUE MUUNT

FIGUKE 1 
the few milimeters fressure of atmospheric water) are completely removed by sending a stream of commercial dry nitrogen through a small tube.

Pigure 1 shows the arrangement; the radiation from the exit slit of the spectrometer enters from the left and is reflected from the plane mirror to the elifpsoidal mirror at the bottom from whence it is focused on the sensitive element of the Golay detector alight]y above the small polyethylene window.

Two other rather importunt improvements were made with a view towards ereater stability. It was observed that the rotatable table upon which the reststrahien filtexing orystuls were mounted had a rather large amount of mechanical play. This table can be rotated to any of four positions by a motor controlled from the outside and thero is a considorable gear train nocessary to link the motor and the tablo. Although the arc of free play was no more than a degree or so it was sufficient to throw the image of the source far enough from its proper position on the entrance slit to make severul percent difference in the energy falling on the detector. The fault was remedied by installing a detent mechanism on the reststrahlen table. A spring loaded ball bearing is forced into one of four shallow conical holes on the under side of the reststrahlen table and so holds the table in one precisely reproducible position for each of the four reststrahlen positions. The original electrical arresting 
apparatus was necessarily also retained. This is a microswitch, the lever of which rides against a cam mounted on the shaft whjch supports the table; thus when the table reaches approximately the correct position the drivine motor stops, and the detent mechanism brings the table into position.

It was thought probable tiat another source of instability might lie in brightness fluctuations of the Golay exciter lamp. This lamp is fed from an automobile storage battery so that one would expect any rapid voltage variations to be slight, but on the other hand the signal output is extremely sensitive to the intensity of the exciter lamp, a one porcent change in lamp potential producing a ten percent change in signal. In order to maintain a more accurate control over the lamp voltage the circuit shown in At the start of a spectroneter run, a meter reading is made and then further readines -- and adjustments if needed -- are made at rogulur intervals during the course of the run. The scheme presupposes stability on the part of the ary cells (E), but this is not unreasonable inasmuch as they aro actually used only during the very brief interval when the testing switch $(S)$ is closed.

All of these modifications have worked quite well in practice and the instrument is now stable to within 2 percent.

A combination of two factors has extended the wavelength range of the spectrometer. A Golay detector with a dianond window has beon received, on loan from the Ijuval 
Research Laboratories. Feretofore a quartz-windowed detector was used which put an upper limit on the frequency range of the spectrometer of about $220 \mathrm{~cm}^{-1}$ as a consequence of the opacity of quartz to higher frequency radiation. The diamond-windowed detector, however, seems to have no marked absorptions down to 13 microns wavelength $\left(670 \mathrm{~cm}^{-1}\right)$.

Also we have received from the University of Michigan a diffraction grating, ruled with 553 lines per inch and blazed at about 30 microns. This srating was installed in the instrument and calibrated usine the theoretical water vapor lines of Randal1, Dennison, Ginsburg and Weber (16) and Benedict (17). Table I bolow gives an indication of the accuracy at present obtainable w1th the instrument. The column headed frequency gives the spectral location. The Reproducibility indicates the magnitude of the frequency difference which occurs between two measures of the same absorption line. This error arises from improper synchronization between the strip chart and the grating drive Veeder counter and from the two percent or so of noise which is present during spectral runs made with the instrument parameters commonly used. There is also a gradual and rather small ( $0.1 \mathrm{~cm}^{-1}$ in most regions) shift in the central image position. By

(16) H. M. Randall, I. M. Dennison, Nathan Ginsburg and Lovis R. Weber, rhys. Rev. 52, 160 (1937)

(17) W. S. Benedict, private comminication, 1950. 


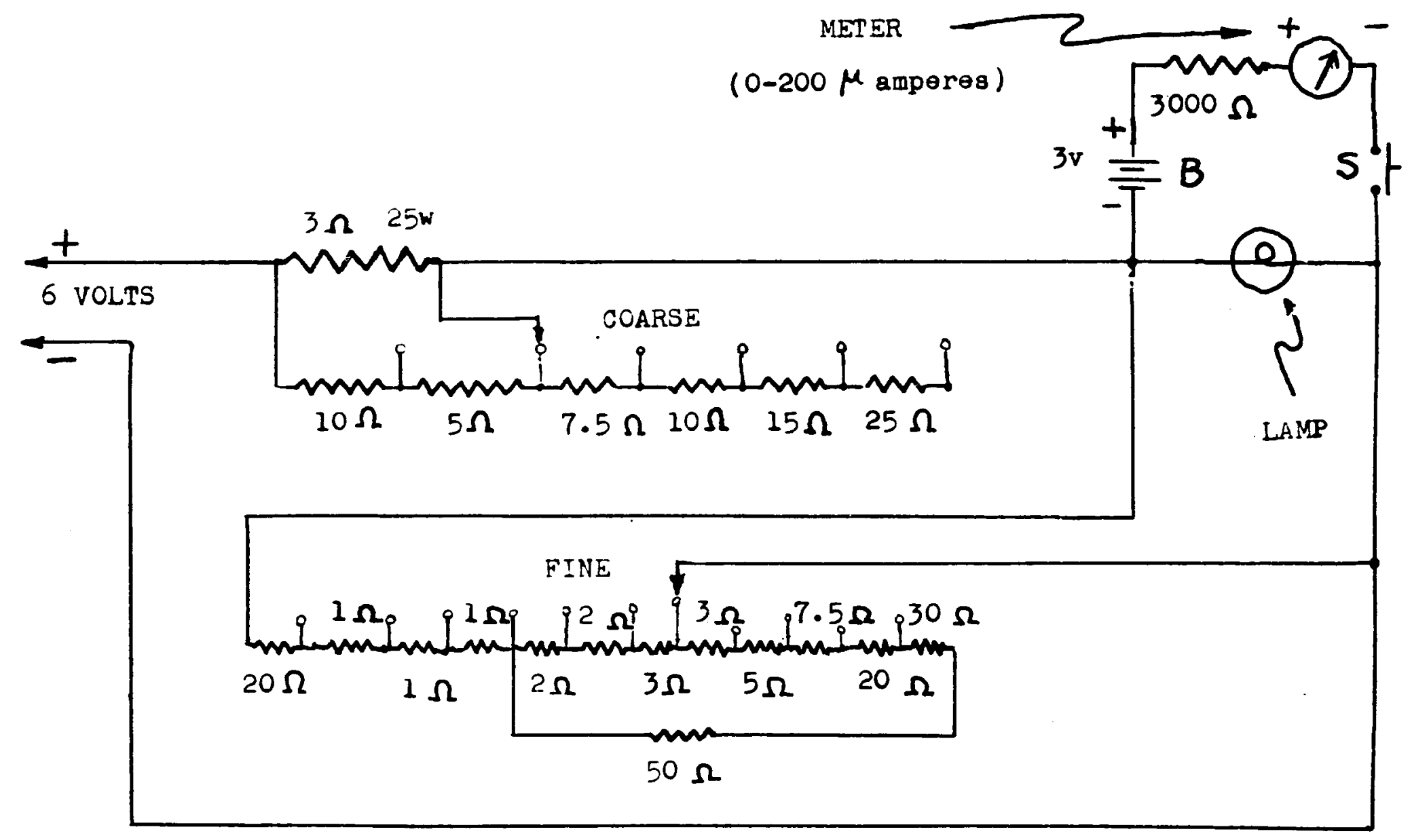

EXCITER LAMP GONTROL

FIGURE 2 
checking the central inage position periodically this can, however, be eliminated as a source of error. The Calibration Accuracy gives the magnitude of the difference between the frequencies of the theoretically predicted water vapor lines and the calibration curve plotted from a mean grating constant. The method of calibration was to measure the angle through which the grating turned (on the assumption that counter readings were linear with angle) in going from the central image to various well defined water vapor lines. From these an effective gratine constant was calculated from the equation

\section{$\sigma\left(\mathrm{cm}^{-1}\right)=K \csc \theta$}

and on the basis of 15 treoretjcally predicted lines scattered throughout the spectral range a mean grating constant was calculated. This constant was then used to construct the calibration table for the instrument.

TABIE I

$\begin{array}{lll}\text { Frequency } & \text { Reproóncibility } & \begin{array}{c}\text { Calibration } \\ \text { Accuracy }\end{array} \\ 100 \mathrm{~cm}^{-1} & 0.02 \mathrm{~cm}^{-1} & 0.01 \mathrm{~cm}^{-1} \\ 200 & 0.08 & 0.02 \\ 300 & 0.05 & 0.09 \\ 400 & 0.10 & 0.12 \\ 500 & 0.16 & 0.15\end{array}$

The sharp chunge between $200 \mathrm{~cm}^{-1}$ and $300 \mathrm{~cm}^{-1}$ is caused by the change in grating used for obtaining spectra in the 
region, below $2 \% 0 \mathrm{~cm}^{-1}$ the 180 line per jnch grating being used and above this frequenoy the 550 line per inch grating. Finally there was constructed a sodium chloride chopper which can be used interchangeably with the previously existing potassium bromide chopper. Sodium chloride is transparent from the visible spectral region out as far as about 18 microns in the thicknesses used for chopper blades. At wavelengths longer tian 18 microns it becomes quite opaque and consequently it is now posible to obtain a workable signal for radiation from this wave length on out to longer wavelengths.

Thus the instmument is now capable of delivering reIiable data over the spectral region between 60 and $500 \mathrm{~cm}^{-1}$ with the accuracies indicated in lable $I$ above.

A further change was made in the instmment in preparation for muning several materials including those which Form the substance of this report. A hole was cut through the boiler plate tanks surroundins the speotrometer; the hole being placed so that its center was directly above a line joining the entrance slit and the center of the spherical mirror immediately preceding the entrance slit. Through this hole it is possible to lower a cylindrical brass pot in the fashion shown in Figure 3 . The cylincer has polyethylene windows on either side of it and a flat plate silver soldered to the top. Thus, when the pot is lowered into position an o-ring under the top plate assures an air 


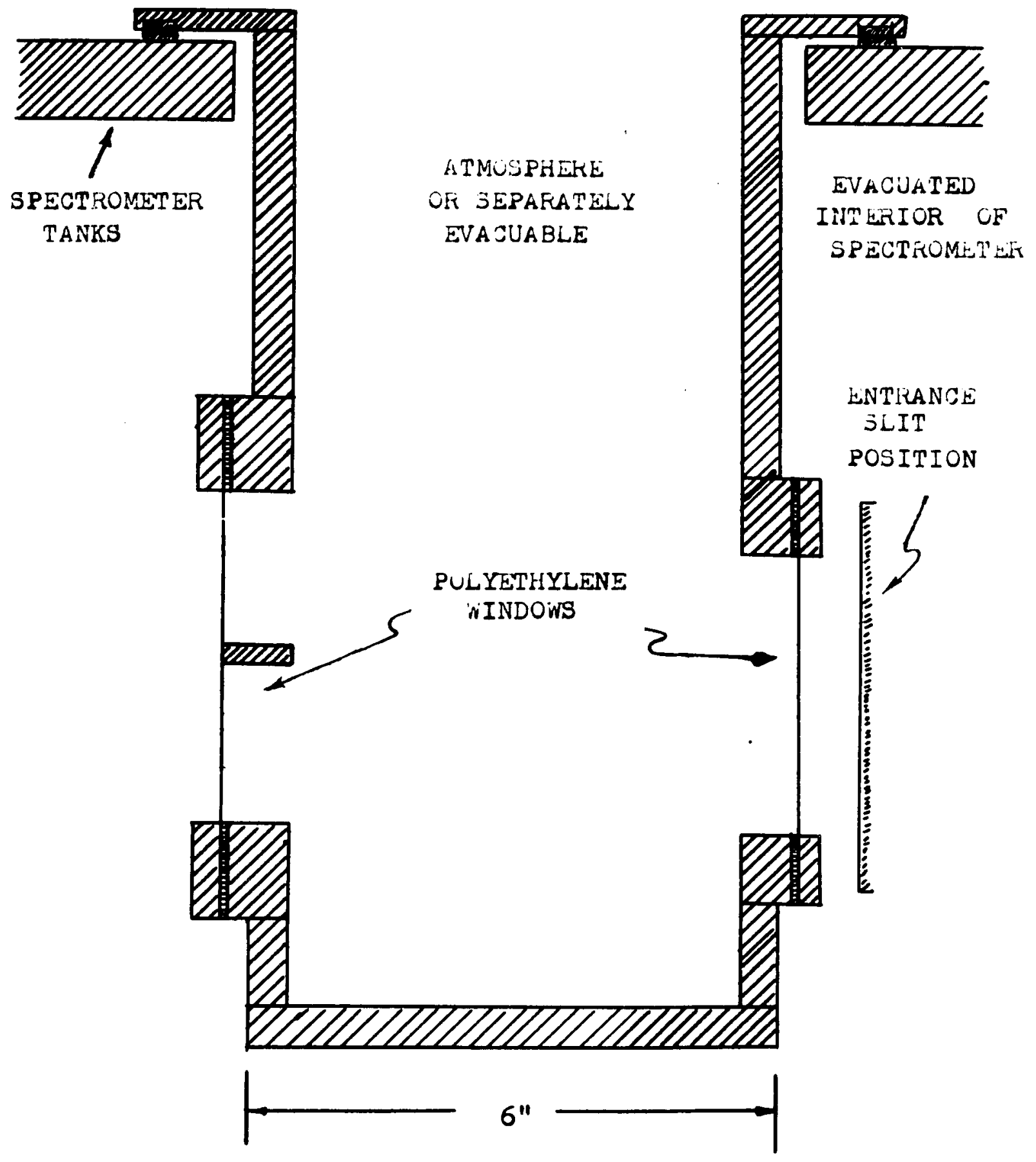

EVA UUABLE THAMBER

FIGURE 3 
tight seal against the spectrometer tank and the windows are aljgned with the radiation path.

The disadvantage of this is that it necessitates two additional windows as well as ribbing across the windows (since there is an areu of six square inches of 0.010 inch polyethylene window across the window). Thus there is a light loss of thirty percent or thereabouts. Welghed against this, however, is the tremendous temporal advantage to having a small chamber, separate from the rest of the spectrometer, which can be evacuated in two minutes and through which a convenient portion of the radiation path is accessible from the outside.

Besides its convenience for introducing solfa samples and the liquia cell (presently to be described) into the radiation path, the pot itself has a diameter of six inches and so can be used as a gas cell.

\section{Samples}

The materials covered in this report are five: the trichlorides of phosphorus, antimony and arsenic and the tribromides of phosphoms and of antimony. 'The pertinent physical constants are given in Table II below (18) (19):

(18) Handbook of Chemistry and Physios, Cleveland, Ohio, 1949. (19) International Critical Tabies, New York, 1943. 
TABLE II

$\begin{array}{lllc}\begin{array}{c}\text { Fielting } \\ \text { Point }\end{array} & \begin{array}{c}\text { Boiling } \\ \text { Point }\end{array} & \begin{array}{c}\text { Vapor } \\ \text { Pressure } \\ \text { (room temp.) }\end{array} \\ \mathrm{PCI}_{3} & -91^{\circ} \mathrm{C} & 75.5^{\circ} \mathrm{C} & 25.0 \mathrm{~cm} \mathrm{IIE} \\ \mathrm{AsCl}_{3} & -18 & 130.2 & 2.6 \\ \mathrm{PBr}_{3} & -40 & 172.9 & 6.4 \\ \mathrm{SbCl}_{3} & 73.4 & 223 & \\ \mathrm{SbBr}_{3} & 96.6 & 280 & \end{array}$

All of these samples were obtained commercially (Mallinckrodt C.P.) and the liquids were used without further purification while the solias were purified by dissolving them in $\mathrm{CS}_{2}$. Both antimony trichloride and antimony tribromide are very soluble in carbon disulfide while the impurities (mainly sbccl from reaction with water) are much less so.

Cells

A fairly simplo techniqu was devised for obtaining the spectra of the solids $\mathrm{SbCl}_{3}$ and $\mathrm{SbBr}_{3}$. A good grade of comercial paraffin was first melted in a beaker, the volume used beine perhaps $20 \mathrm{~cm}^{3}$. Such parafin has no sharp melting point, but at the temperature at which it is reduced to a watery consistency it is something above $100^{\circ} \mathrm{C}$ and thus well Ebove the melting points of the two solids considered. Tothe molten parafin was added a small sample of purified 
$\mathrm{SbBr}_{3}$ or $\mathrm{SbCl}_{3}$, which would theroupon melt and dissolve. It is important that these solid trihalides be purified in the manner indicated above, otherwise when this mixing is carried out a considerable residue will be left and the entire melt will become tinged with red, causing general spectral absorptions.

The melt is next poured onto a confined surface of mercury which has been previously heated so that solidification will not uake place upon contact. After cooling, the parafin-plus-sample disc is removed and can then be placed in the light path and the spectrum run.

The parafin tochnique was used out of necessity. The trihalides are very nearly insoluble in all the common nonpolar solvents (polar solvents are opaque at these frequencies) and with present window materials it is not possible to run the cell at a high enough temperature to melt the $\mathrm{SbCl}_{3}$ or $\mathrm{SbBr}_{3}$. Powders simply scatter all of the radiation. The problem of designine a liquid cell for use in this spectral region was solved reasonably well although there is need for improvement. The general requirememts for such a cell are no different from those for a near infrared Iiquid coll. Here it is absolutely necessary that the cell can be relied upon to remain tightly sealed for considerable periods in a vacuum. This necessity arises from the difficulty in completely removing water vapor from the light path. Commercially dry gases (such as ary nitrogen) show water vapor 
absorptions for path lengths of more than a few inches and, while dessicants such as $\mathrm{P}_{2} \mathrm{O}_{5}$ will eventually ary a chamber of no more than a few cubic feet in volume, the time required is usually several hours. Thus it seemed most expedient to devise a cell which could be flaced in the evacuable pot, the drying process being reduced in this fashion to a matter of a few minutes.

The main difficulty in the construction of the liquid coll is that there are so few satisfactory window materials in the far infrared. The most transparent substances are long chain hydrocarbons such as paraffin, mineral oil and the classic window material, polyethylene. We use the latter throughout and it is quite satisfactory in the way of transparency and strength and (for the most part) inertness; qualIties which make it admirable for cas cells; but it has the drawback of being flexible. The erea of the beam at the point where the samples were introduced is about $2 \frac{1}{2}$ "by $I^{\prime \prime}$ and the vapor pressures of the liquids ranged up to $1 / 6$ atmosphere at room temperature (Table II). This large a pressure, even with polyethylene $0.035^{\prime \prime}$ thick, would cause bulging of the polyethylene window so that the liquid level would be lowered and part of the radiation beam would pass through the empty cell when the cell was placed in a vacuum. It would have been possible to arrange a cell with a surficiently large reservoir capacity to prevent such an extreme drop in liquid level; incieed sometring of this sort 
was actually tried but the bulging caused defocusing to an extent that made the method impracticable.

Another difficulty was that of getting a suitable spacer between the windows. It had to seal tightly enough to the polyethylene to prevent any leaking at the vapor pressures of the liquids and in addition it had to be at least as inert as (and preferably more so than) polyethylene. Polyethylene itself was used as a spacer for the AsCl; cell; however, it is necessary to use a wax to form a seal between the polyethylene surfaces, since the substance will not serl tightly to itself. The arrangement finally settled upon is shown in Figure 4 in the exploded drawing of the cell components. The outside sections are coarse wire screen with a wire diameter of $1 / 32^{\prime \prime}$ and a screen spacing of $1 / 4 "$. The spacer was cut from 0.048 " Koroseal and presented a crosssectional window area of $I^{\prime \prime} x 2^{\prime \prime}$ wich is slightly smaller than the beam size at this point. However, the Golay detector as presontly arranged has a sonsitive aroa which encompasses only about a third of the total radiation incident on the detector nose. Hence the cell is large enorgh to include all of the usable beam. The wire screen has a geometric opacity of $30 \%$ and the actual opacity is very close to this. Hy carefull.y aligning the screens whenever the cell was assembled the light loss with two windows was very little more than with a single window.

The windows themselves were of $0.035^{\prime \prime}$ polyethylene and 


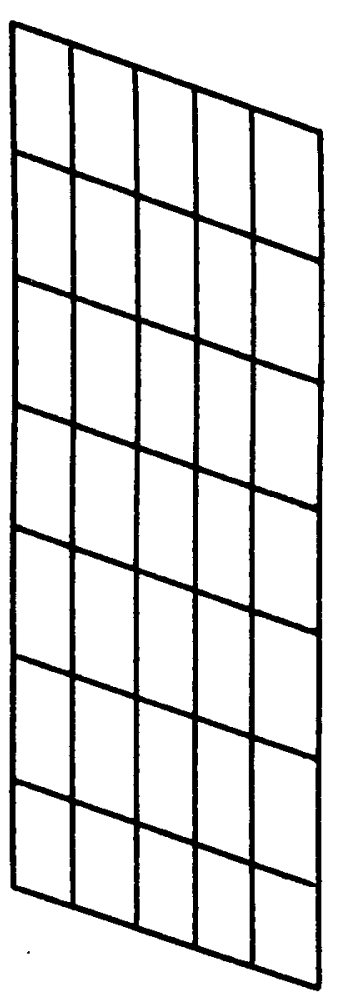

WIRE SCREEN

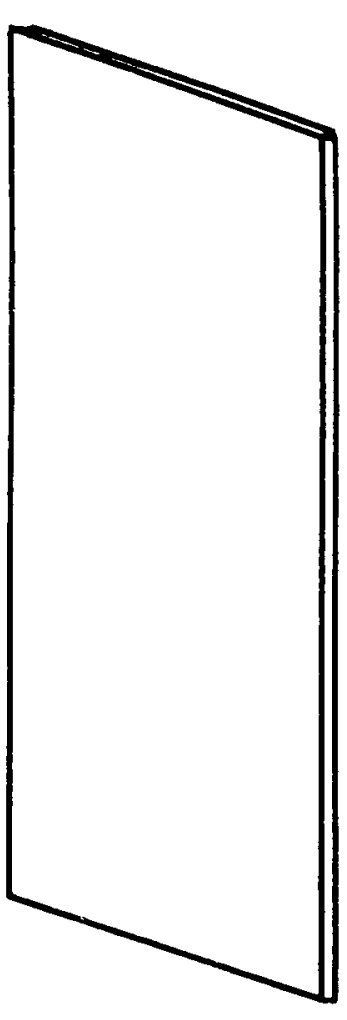

POL YETHYLENE WINDOW

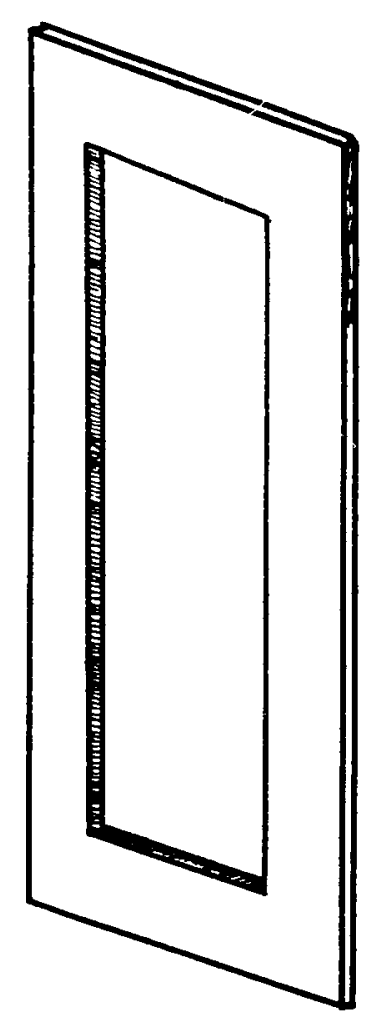

KOROSEAL SPACER

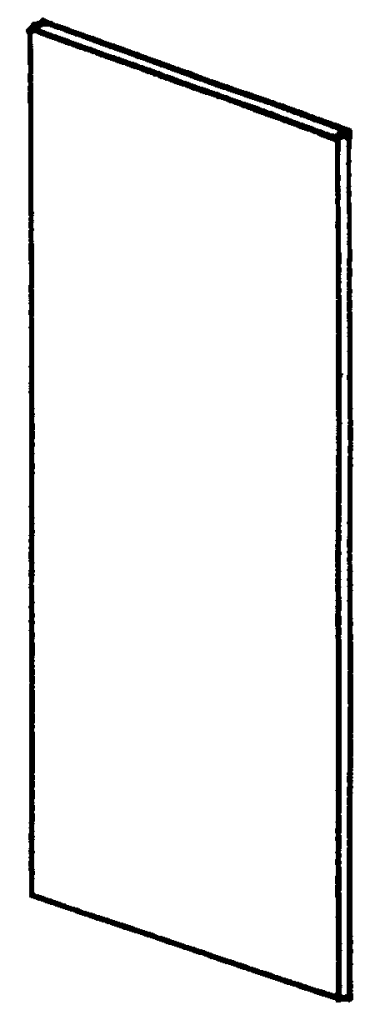

POLYETHYLENE WINDOW

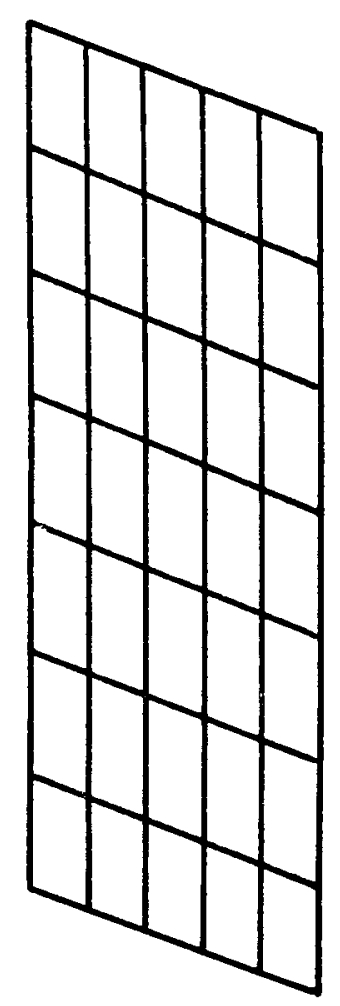

WIRE SCPEEN

LIQUID CELL COMPONENTS FIGURE 4 
were sufficiently rigid that when used with the grating reinforcers neither severe defocusing nor troublesome drop in the liquid level occurred when the cell was introduced into the pot and the pot evacuated. It should be remarked that polyethylene, while chemically inert with respect to these liquids, did show a tendency to absorb them and the cell would, over a period of several hours, lose a good fraction of it, contents from the liquid soaking through the polyethylene window and evaporating to the outside. Alnost all of the data runs were of an hour's duration or less so that in this investigation the effect was not overly bothersome. It does mean that one is constantly pumping a little of the trihalide vapor through the vacuum pumps, a process which causes very rapid disintesration of the pump oil. To actually form the cell the components shown in Figure 4 were clamped together in the arrangement shown in F-gure 5. At the time of assembly a hypodermic needle is left inserted between the components as shown in the sketch. The liquid is introduced into the cell through this neodle after which the needje is withdrawn and the front clamping plate drawn up tight. It is of considerable importance that the needles be thoroughly rinsed afterwards with ethyl alcohol, otherwise chemical action will destroy the needles after two or three usings. The cell assembly shown in Figure 5 has the purpose of not only holding the cell components tightly together and 


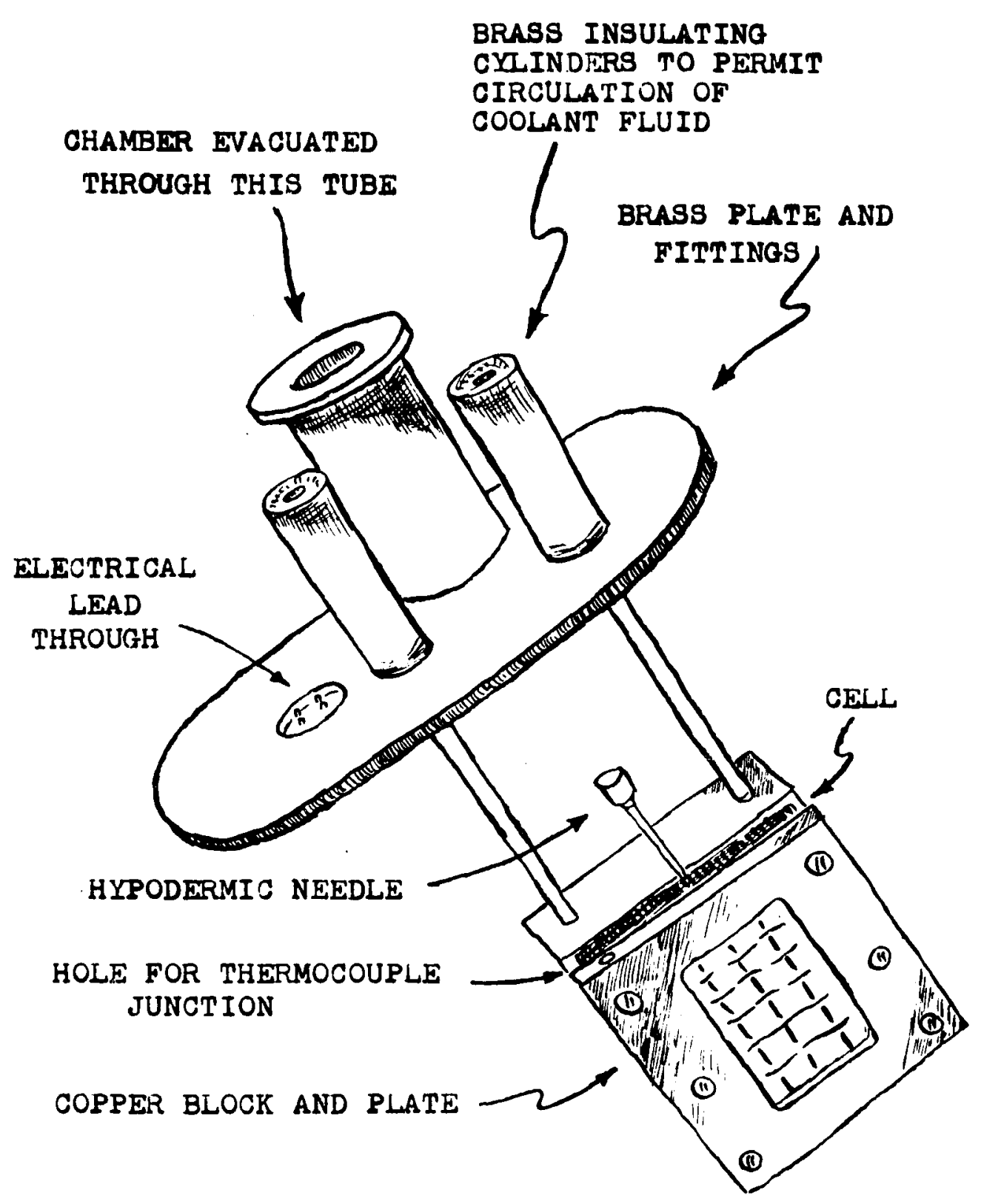

LIQUID CELL ASSEMBLY

FIGURE 5 
placing them properly in the beam, but also allowing the samples to be run at different temperatures. The rods holding the lower copper cell clamping assembly to the upper brass fitting are hollow stainless steel tubes, silver soldered both to the copper block and to the brass cylinders above. A cross sectional view of the construction j.s shown in Figure 6. The cylindrical brass extensions at the top are made with a view to having the thermal puth between the copper block and the spectrometer tanks as long as can be conveniently arranged. By circulating liquid of the desired temper. ature through the tubing the copper block, and hence the sample, can very quickly be brought to the same temperature. Tre principal restricting factors in all this are the properties of polyethylene at extreme temperatures. Above $100^{\circ} \mathrm{C}$ it becomes soft and loses strength rapidiy with increasing temperature; for low temperatures, however, the situation is a good deal more satisfactory. iven when inmersed in liquid nitrogen $\left(-196^{\circ} \mathrm{C}\right)$, polyethylene remains somewhat pliable and is not seriously weakened.

A small hole was arilled into the clamping plate as indicated in the Iigure, and into this was inserted a copperconstanan junction. The thermocouple leads were taken out throwh the electrical leadthrough also shown in ligure 6 , and the other junction placed in melting ice. A fairly rough calibration made with iso-octane, liquid nitrogen, and a salt-ice-water mixture eave enough points to be able to 


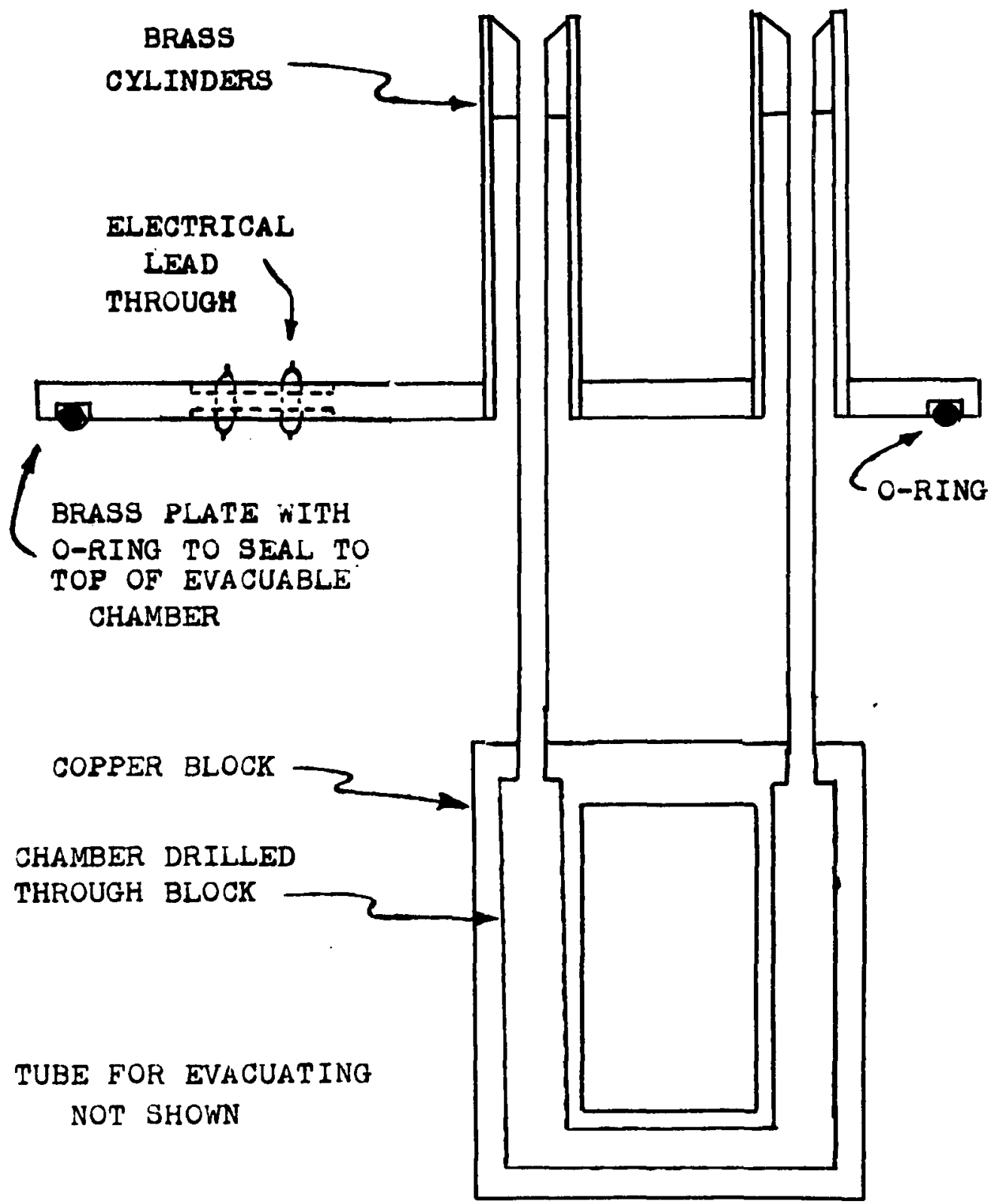

CROSS SECTION OF CELL ASSEMBLY

FIGURE 6 
establish a curve sufficienty good to determine the cell temperature to within $10^{\circ} \mathrm{C}$. Ihis could be much impro ved with a more carefully measured calibration.

No spectral measurements of substances at low temperatures have as yet been made with the system except for a spectrum made between 50 and 70 microns with the empty ceII at the temperature of liquid nitrogen. This was done to determine whether the polyetrylene would undergo any phase transitions which would affect its transparency for far infrared radiation at low temperatures. No changes in transparency were observed. 


\section{THEORY}

\section{Group Theory}

This family of molecules, like ammonia, belongs to the point group $\mathrm{C}_{3 v}$, which is to say it has a threefold (vertical) axis of rotational symmetry and three vertical reflection planes. Figure 7 shows the covering operutions possible with this type of molecule.

The Group elements are

$$
\begin{aligned}
\varepsilon= & \text { identity } \\
C_{3}= & \text { rotation by } 120^{\circ} \text { about } z \text { axis } \\
C_{3}^{2}= & \text { rotation by } 240^{\circ} \text { about } z \text { axis } \\
\sigma= & \text { reflection in } x z \text { plane } \\
\sigma^{\prime}= & \text { reflection in a plane containing the } \\
& \text { symmetry axis and making an angle of } \\
& 60^{\circ} \text { with the } x-a x i s . \\
\sigma^{\prime \prime}= & \text { reflection in a plane containing the } \\
& \text { symmetry axis and making an angle of } \\
& 1200 \text { with the } x-a x i s .
\end{aligned}
$$

If we now define the product of two of the group elements to be the single operation which has the sume result as that produced by one of the group operations followed by another of the operators, then we can arrunge a multiplication table in which the column headings are those operations carried out first and the row headings those carried out second. The operator at the intersection of the row and column is the operutor which is equivalent to the 


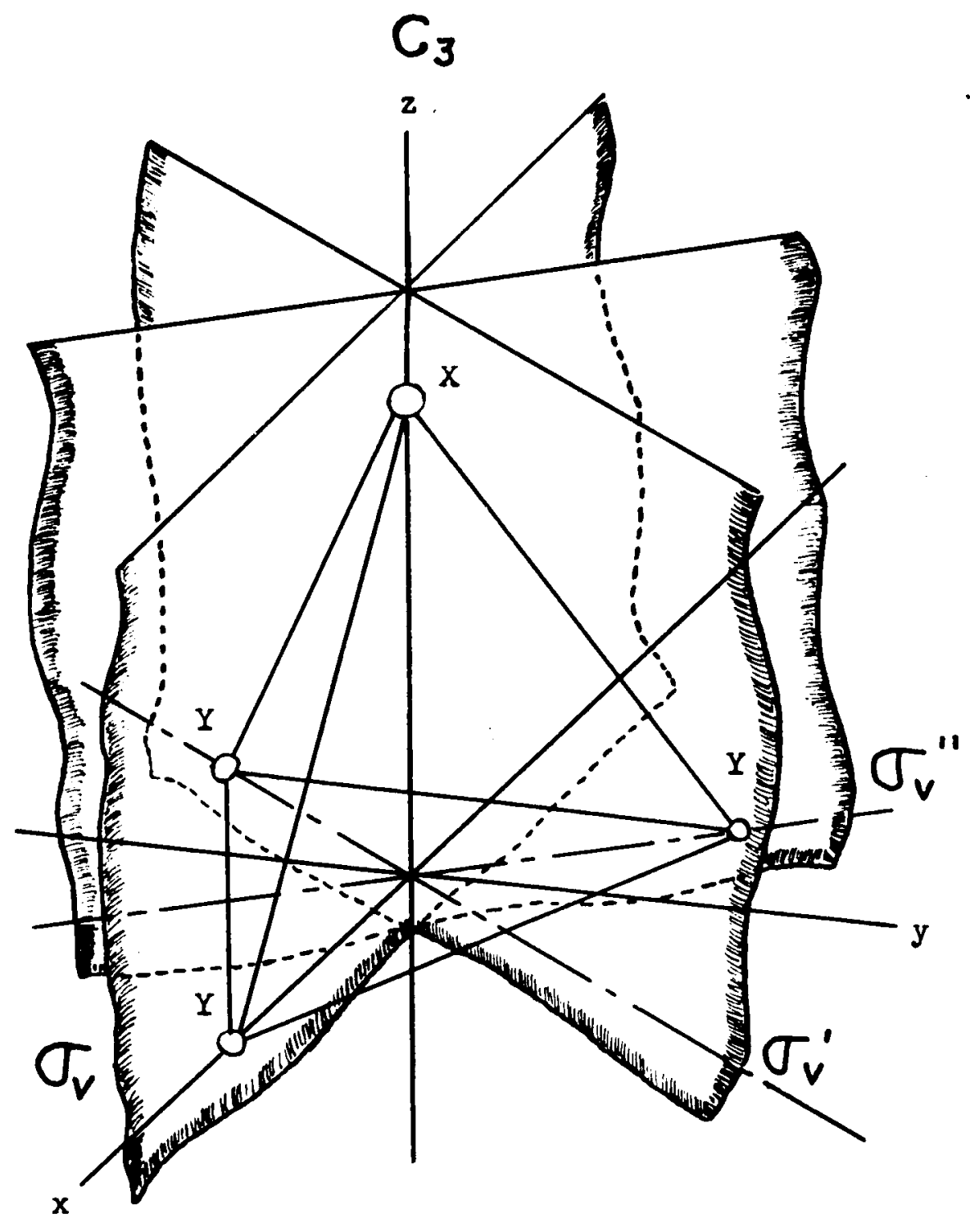

SYMMETRY ELEMENTS OF THE $C_{3 V}$ GROUP FIGURE 7 
two operations carried out in succossion. This is shown in Table III:

TABIE III

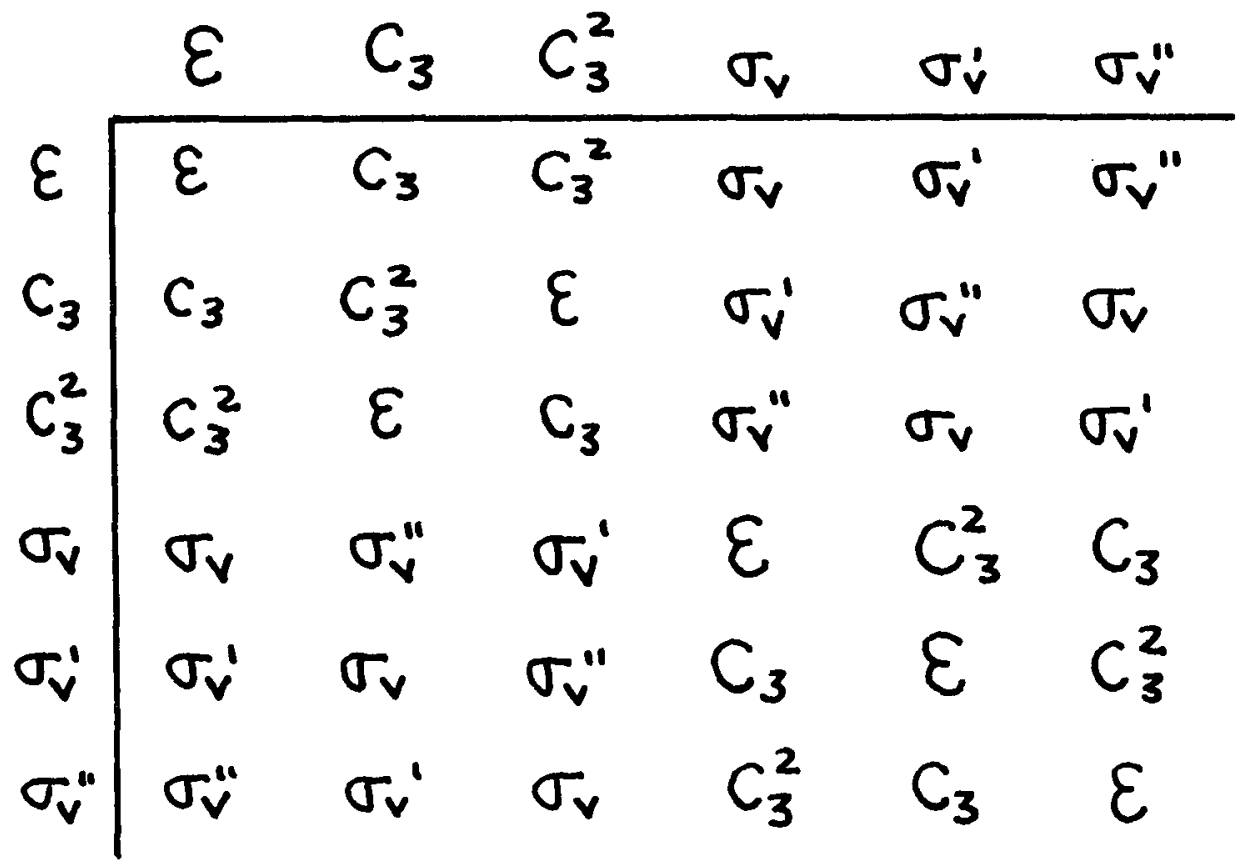

The "classes" of elements comoosing a group are defined as those elements $x_{i}$ which are transfomed among themsel ves by the transformation $X_{1}=Y^{-1} X_{j} Y$ where $Y$ is any element of the group, the group multiplication operation was defined above and the element standing to the right represents the first operation to be carried out. For this group we find that the elements are formed into the classes

$$
\{\varepsilon\},\left\{C_{3}, C_{3}^{2}\right\},\left\{\sigma_{v}, \sigma_{v}^{\prime}, \sigma_{v}^{\prime \prime}\right\}
$$

It can be shown that to every group there is a simply isomorphic group of matrices and since the $C_{j v}$ is a group 
formed by geometric operations we can construct the elements of its isomorphic matrix group simply by writing out the transformation matrices for the covering operations. For example from the planar rotation matrix

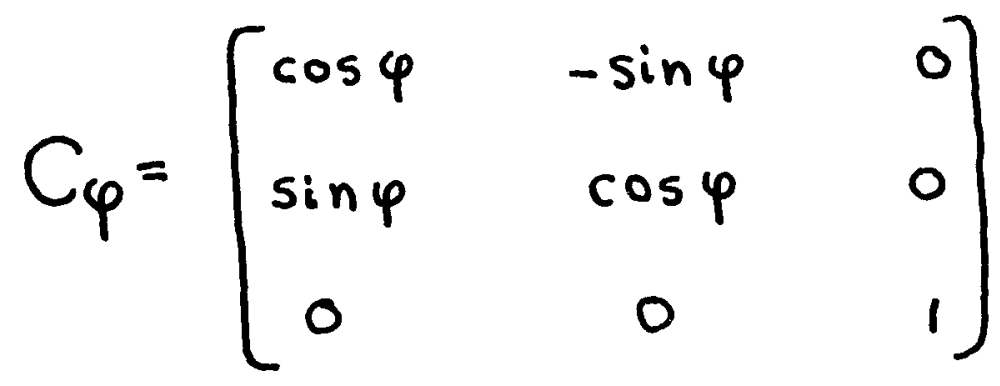

we obtain the $\mathrm{C}_{3}$ and $\mathrm{C}_{3}^{2}$ matrices. The three reflection matrices can either be obtained by considering what happens to each of the coordinates under the reflection operations or more formally by using the rotation matrices and the multiplication table. The matrices isomorphic to the $\mathrm{C}_{3 \mathrm{~V}}$ is roup are then

$$
\begin{aligned}
& C=\left[\begin{array}{ccc}
1 & 0 & 0 \\
0 & 1 & 0 \\
0 & 0 & 1
\end{array}\right] \quad C_{3}=\left[\begin{array}{ccc}
-\frac{1}{2} & -\frac{\sqrt{3}}{2} & 0 \\
\frac{\sqrt{3}}{2} & -\frac{1}{2} & 0 \\
0 & 0 & 1
\end{array}\right] \\
& C_{3}^{2}=\left[\begin{array}{ccc}
-\frac{1}{2} & \frac{\sqrt{3}}{2} & 0 \\
-\frac{\sqrt{3}}{2} & -\frac{1}{2} & 0 \\
0 & 0 & 1
\end{array}\right] \quad \sigma_{v}=\left[\begin{array}{ccc}
1 & 0 & 0 \\
0 & -1 & 0 \\
-\frac{1}{2} & \frac{\sqrt{3}}{2} & 0 \\
\frac{\sqrt{3}}{2} & \frac{1}{2} & 0 \\
0 & 0 & 1
\end{array}\right] \\
& \sigma_{v}^{1}=\left[\begin{array}{ccc}
-\frac{1}{2} & -\frac{\sqrt{3}}{2} & 0 \\
-\frac{\sqrt{3}}{2} & \frac{1}{2} & 0 \\
0 & 0 & 1
\end{array}\right]
\end{aligned}
$$


which will then give the $C_{3 v}$ multiplication table under the operation of matrix multiplication.

Now it may happen that the matrices isomorphic to a group can be "reduced", which is to say they can be put into a form wherein each matrix is composed of a number of submatrices arranged along its diagonal. Thus

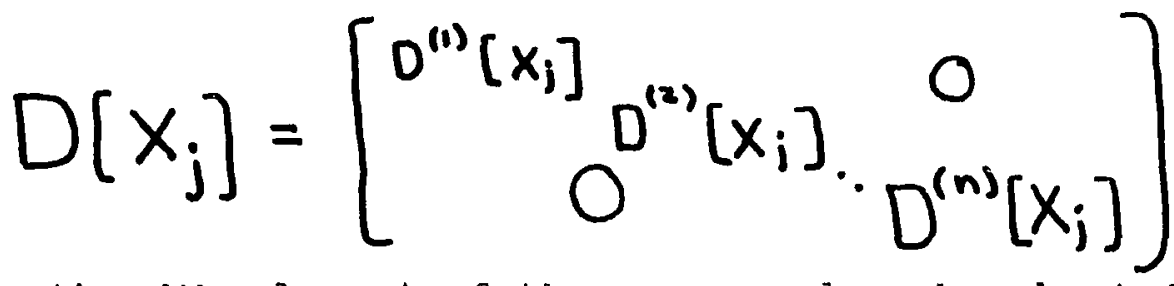

where $x_{j}$ is the $j$ th element of the group and each submatrix $D^{1}\left(x_{j}\right)$ is also isomorphic to the group element $x_{j}$.

This reduction, if possible, is performed by means of a similarity trunsformation, that is $G^{-1} \mathrm{D} G$, where $G$ is an orthogonal matrix. It is a property of such a similarity transformation that it leaves the sum of the diagonal elements invariant, for

Trace $\left(G^{-1} G\right)=\sum_{i} \sum_{m} \sum_{l} G_{i l}^{-1} D_{l m} G_{m i}$, and since
Gis orthogonal $\sum_{i} G_{m i} G_{i l}^{-1}=\delta_{m l} \quad$ where $\delta_{m l}=\begin{aligned} & 01 \neq m \\ & 1 \quad l=m\end{aligned}$ and we have that Trace $\left(G^{-1} \bar{D} G\right)$ is equal to lrace $D$. iforeover, since elements of the same class are obtained from each other by similurity transformations, it follows that all matrices isomorphic to elenents constituting a class are characterized by having the same trace. If, then, we take a matrix group simply isomorphic to 
our geometric group and reduce it completely -- that is, until the submatrices on the diufonals of our resulting matrices cumot all be further reduced by a similarity transformation -- we shall have obtuined some (but not necessarily all) of the irreducible representations of the group. The following orthogonality relation can be shown (20) to hold between the irreducible representations

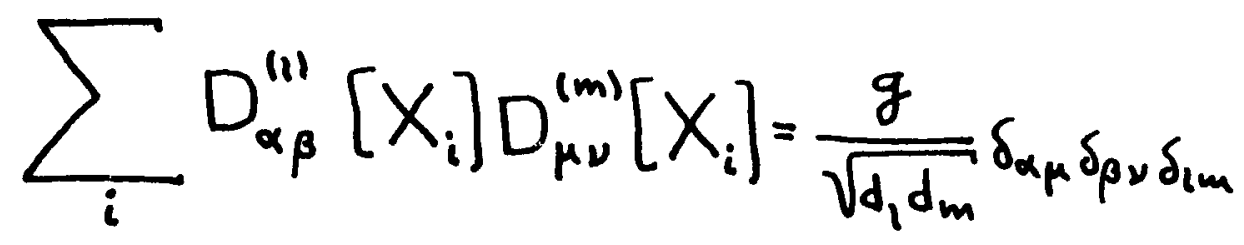

where $x_{1}$ is the corresponding group element, the superscript indicates which of the irreducible representations is meant, and the subscripts indicate row and column of the irreducible representation. The $d_{m}$ is the dimension, i.e., the number of rows or columns of the squure matrices which are the mth irreducible representation, and the syrabol $\&$ is the number of elements in the group.

Also, if there are $\mathrm{g}$ classes in the group, there will be $s$ different irreducible representations and the sum of the squares of the dimensions will equal the order of the group, that is

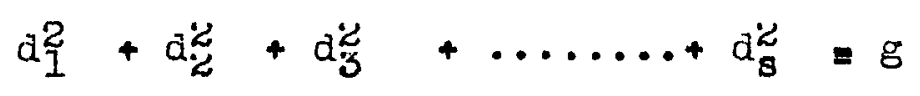

It is a happy fact that the results available from group theory for spectroscopy can be obtained without a (20) Walter, Eyring, and Kimball, op. cit. 
knowledge of the irreducible representations themselves but from their traces, or characters, to use the more usual terminology in group theory. Futting the quantities with which we are dealing in the form of an array we have

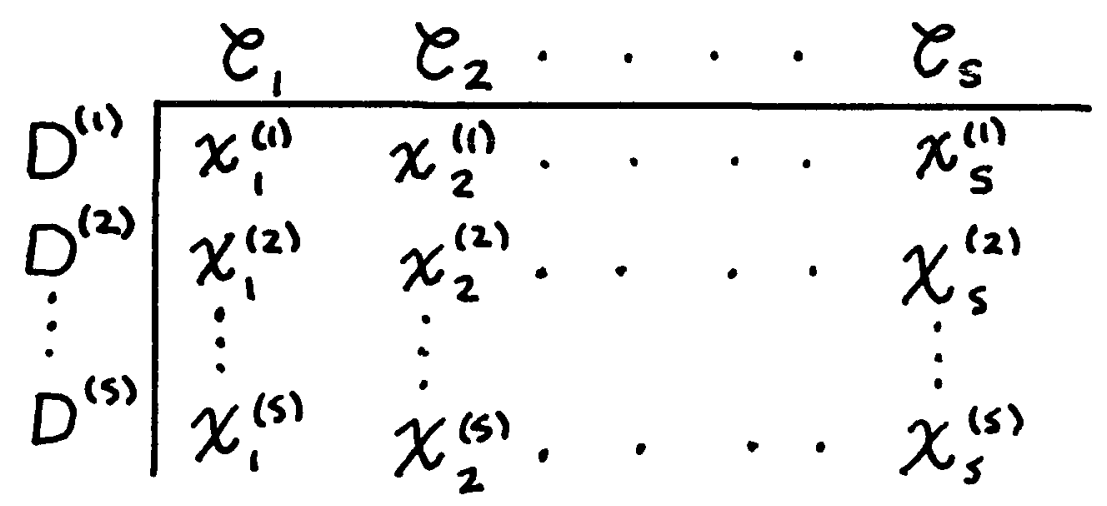

where the $\mathcal{X}_{m}^{(i)}$ is the character of matrix isomorphic to the elements of the mth class (denoted by $\boldsymbol{C}_{m}$ ) and belongine to the ith irreducible representation (denoted by row heading $\left.D^{(i)}\right)$

One car, by lising a method outinned in (21), derive the group characters from a knowledge only of the multiplication table of the group. For the $\mathrm{C}_{3 \mathrm{~V}}$ group this results in the table below which is just a special case of the array above:

TABIE IV

\begin{tabular}{|c|c|c|c|}
\hline & $\varepsilon$ & $2 C_{3}$ & $3 \sigma_{V}$ \\
\hline$A_{1}$ & $I$ & 1 & 1 \\
\hline$A_{r}$ & 1 & 1 & -1 \\
\hline $\mathrm{E}$ & $\ddot{z}$ & -1 & 0 \\
\hline
\end{tabular}

(2I) H. Iargenau and $G$. Hurphy, The Rathemat1cs of Fhysics and Chemistry, liew York, $19 \overline{45}$ 
The column headings givo a typical momber of the class and the number of elements in the class. The row headings give all of the irreducible representations for the $\mathrm{C}_{3 \mathrm{v}}$ group where we have replaced the $D^{(m)}$ of the previous general array with the usual spectroscopic notation; nondegenerate (i.e., I $\mathrm{x}$ l) representations are denoted by $\mathrm{A}$ and doubly degenerate $(2 x 2)$ ones by E. The subscripts on the $A^{\prime} s$ indicate their symmetry with respect to reflections in the vertical planes.

The thorough treatment of the application of group theory to the quantum mochanical prediction of spectry is somewhat lengthy but quite straightforwara. In its barest essentials the theory rests on the fact that a coordinate trunsformation operator, such as the eroup elements we huve been considering, act upon the Schrödinger eigenfunctions in such a fashion as to produce irreducible representations of the group. The meaning of this will be seen a littie more clearly in the following; let us express some one of our covering ope:ations by $R$ and allow it to operate on the Schrödinger equation for the ith energy level, thus $R\left(I I \boldsymbol{\Psi}_{i}-E_{i} \boldsymbol{\Psi}_{\mathbf{i}}\right)$ $=0$. For a conservative systom the Faniltonian is a functional expression of the total energy and so cannot be dependent on the coordinate description of the system, whence $R$ and $H$ must commute. Since $E$ is a constant we have then $\mathrm{HR} \Psi_{i}-\mathrm{E}_{i} R \Psi_{i}=0$, thut is, the functions obtained by operating on the eigenfunctions of the Hamiltonjan with a covering 
operator are also eigenfunctions of the Hamiltonian and beyond thut also correspond to the same energy levels. For the nondegenerate case, since our eigenfunctions must be normalized we have that $R \Psi_{i}= \pm \Psi_{i}$, and indeed, this operution does produce all of the irreducible representations contained in Table IV for the two 1 x 1 irreducisle representations, $A_{I}$ and $A_{.} \cdot$

If we are dealing with a degenerate eigenvalue the situation is more involved. Here we have that the operator $X_{n}$ produces a linear combination of the degenerate eigenfunctions

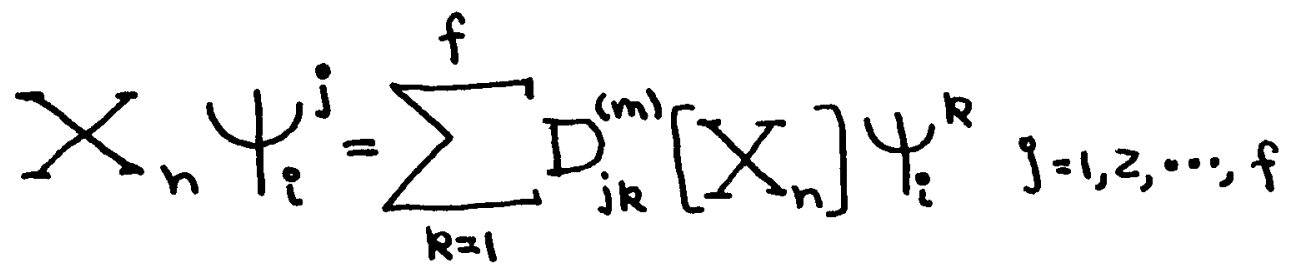

wherein $\Psi_{i}^{j}$ is the $j$ th function of the $i$ th eigenvalue and the $D_{j k}^{(m)}\left[X_{n}\right]$ are the expansion coeficicients which also, when collected into a matrix, form one of the irreducible representations of the group. In this case we have assumed it to form the inth one.

The oigenfunctions are said to form a basis for the Group and for the case of a molecule with only hamonic forces the eigenfunctions have the form (22):

(22) Walter, Eyring, and Kimball, op. cit. 


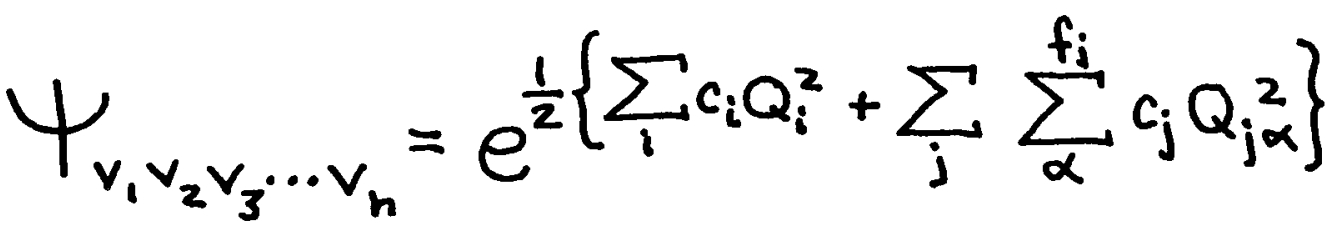

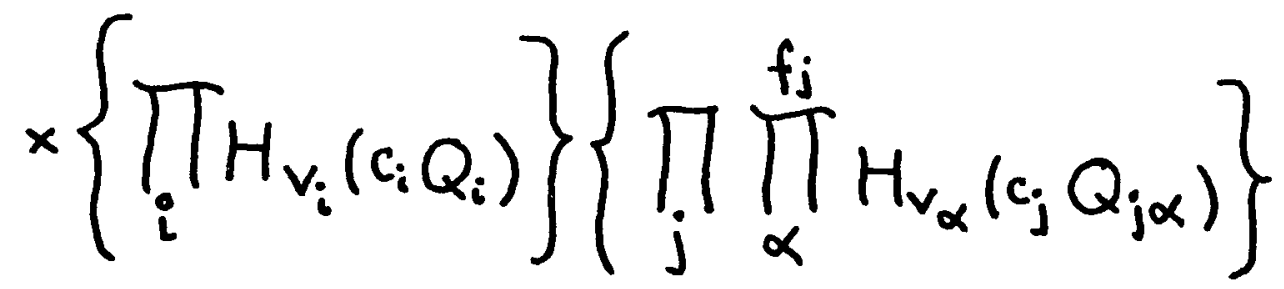

where $f_{j}$ is the degeneracy of the $j$ th energy level and $c_{i}=\left[\frac{\nu_{i}}{h}\right]^{1 / 2}$ The $Q^{\prime}$ s are the normal coorainates soing with. each classical normal mode of vibration of frequency (in the case of degeneracy there will be more than one normal coordinate for each frequency; this is indicatod by the second subscript on the Q's for the degenerate vibrations). The $\mathrm{H}_{\mathrm{V}}(\mathrm{CQ})$ are the hermite polynomials as functions of the various coordinates $c_{j} Q_{i}$ and $c_{j} Q_{j} \alpha$.

We next need a result proved in (23) (page 187) that a product of characters can be written as a sum of the characters of the irreducible representations. Thus, from Table IV above we see that if we write out the characters of the Irreducible representations for all the group operations we huve, for example:

(23) Walter, Eyring, and Kinball, 으. it. 


\begin{tabular}{|c|c|c|c|c|c|c|}
\hline & $\varepsilon$ & $\mathrm{C}_{3}$ & $C_{3}^{2}$ & $\sigma_{v}$ & $\sigma_{v}^{\prime}$ & $\sigma_{v}{ }^{\prime \prime}$ \\
\hline $\mathrm{E}$ & 2 & -1 & -1 & 0 & 0 & 0 \\
\hline$E$ & 2 & -1 & -1 & 0 & 0 & 0 \\
\hline $\mathrm{HE}$ & 4 & 1 & 1 & 0 & 0 & 0 \\
\hline
\end{tabular}

or $\mathrm{EE}=A+A+E$ and other products may be worked out in a similur fashion.

In order to find the forms of the vibrations permitted by the symnetry of the molecule it is necessary to find the character of the vibrational representation. This is (24) the trace of that matrix which transforms the vibrational coordinates under one of the group operators. To find this character we must first consider the matrix which transforms arbitrary displacements of the atoms in the molecule under the varjous covering operations which form the group. This matrix we term the displacement matrix and its trace the displacement character. In our $x x_{3}$ case we would have, for example, a column vector of the form $\left(\delta x_{I}, \delta y_{I}, \delta z_{I}, \delta x_{2}\right.$, $\left.\delta y_{2}, \delta z_{2}, \delta x_{3}, \delta y_{3}, \delta z_{3}, \delta x_{4}, \delta y_{4}, \delta z_{4}\right)$ wherein a $\delta x_{1}$ describes an instantaneous displacement of the ith particle in the $x$ (space fixed) direction during the motion of the molecule. The only atoms in the molecule which will contribute to this trace are those which the covering operation will not interchange with other atoms in the molecule. In a $\mathrm{C}_{3}$

(24) Mimeographed notes of Professor W. I. Shaffer, The Ohio State iniversity, 1948. 
rotation about the symmetry axis, for example, the motion of the three base atoms, which all move on to equivalent positions, will be represerted by only off alagonal elements in the transfomation matrix. The peak atom, on the other hand, will have its displacement vector transformed by a $3 x$ is matrix lying on the diasonal of the complete displacement transformation matrix. Quantitatively the identity operator will have the trace 12 and the rotation operators $1+2 \cos 120^{\circ}$. To obtain the trace of the reflection operator we can consider the simple case in which the vertical reflection plane contalns one of the horizontal axes, say the $x$ axis. Then, if we label the atoms \#l for the peak $X$ atom and $\# 2, \# 3$, and $\# 4$ for the three $Y$ atoms we shall have: $\delta z_{1}+\delta z_{1}, \delta x_{1} \rightarrow \delta x_{I}, \delta z_{2} \rightarrow \delta z_{2}, \delta x_{2} \rightarrow \delta x_{2} ;$ but $\delta y_{1} \rightarrow-\delta y_{I}$ and $\delta y_{Z} \rightarrow-\delta y_{Z}$ and the trace is $z$. Thus, using $\Gamma_{D}$ as the displacement character (we reserve the $D$ symbol for irreducible representations):

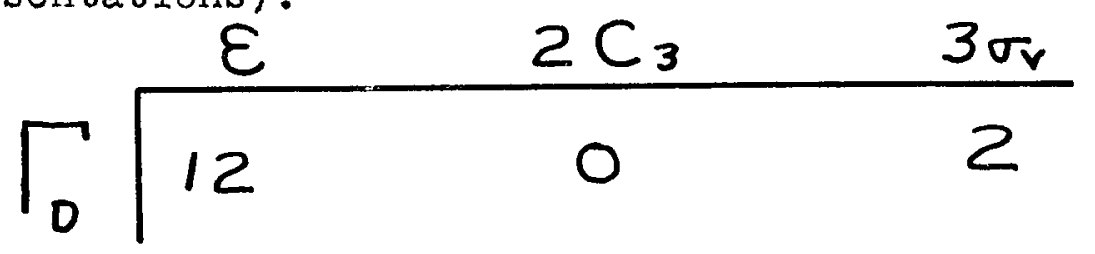

and this can be reduced to a sum of irroiucible representutions either by an inspired inspection or by an orthogonality relation derivable from the one between the components of the irreducible representations jiven on Fage 31 above. The relation between the characters is: 


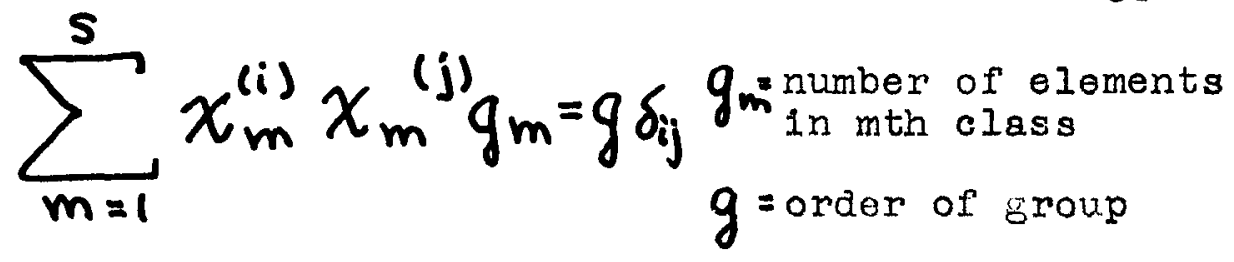

and since any character can be expanded from the irreducible churacters (25) in the form

$$
\chi_{m}=\sum_{i=1}^{s} a_{i} \chi_{m}^{(i)}
$$

we can obtain the coefficients $a_{i}$ by the usual method for expansion in orthogonal functions. In any event the displacement character when expanded is

$$
\Gamma_{0}=3 A_{1}+A_{2}+4 E
$$

Which is not, at yet, the vibrational character in that we still have included the translations and rotations of the whole molecule. The procedure for eliminating these characters is indicated in the following paragraphs ( 26$)$.

From the coordinute transformation matrices wo obtained on Page 29 above we see that (since the column vectors upon which the matrices act are in the usual form (x, y, z)) $z$ transforms as $\mathbf{A}_{1}$ and that the coordinate pair $(x, y)$ transforms tocether as E. This suffices to dispose of the characters for pure translation which is merely a vector displacement (x, $y, z)$.

For the rotational characters, we must consider how an axial vector such as the angular momentum transforms under

(25) Walter, Eyring, and Kimball, op. cit. (26) cf. Waltor, Lyrine, Kimball, op. iㅗ., and shaffer, mineographed notes. 
the group operations. This can be done by finding the transformation coefficierts for each of the components of the infinitesimal rotation vector $R_{x}=y \delta z-z \delta y$ and forming these coefficients into the transformation matrices going with each of the covering operations. Fhen this is done we find that the vector $\left(R_{x}, R_{y}, R_{z}\right)$ transforms under our $\left[\begin{array}{lll}1 & 0 & 0 \\ 0 & 1 & 0 \\ 0 & 0 & 1\end{array}\right]\left[\begin{array}{ccc}\cos 120^{\circ} & -\sin 120^{\circ} & 0 \\ \sin 120^{\circ} & \cos 120^{\circ} & 0 \\ 0 & 0 & 1\end{array}\right]\left[\begin{array}{ccc}-\cos 2 \times 60^{\circ} & -\sin 2 \times 60^{\circ} & 0 \\ -\sin 2 \times 60^{\circ} & \cos 2 \times 60^{\circ} & 0 \\ 0 & 0 & 1\end{array}\right]$

$60^{\circ}$ being the angle that the intersection of the vertical reflection plane and the $x y$ plane makes with the $x$-axis. We are now equipped to give the character table showing the characters of the rotations and coorainates and products of coordinates (the latter from the matrices which transform "vectors" of the type $\left(x^{2}-y^{2}, x y\right)$ etc. according to the group operations) going with each of the irreducible representations:

\section{TABLE V}

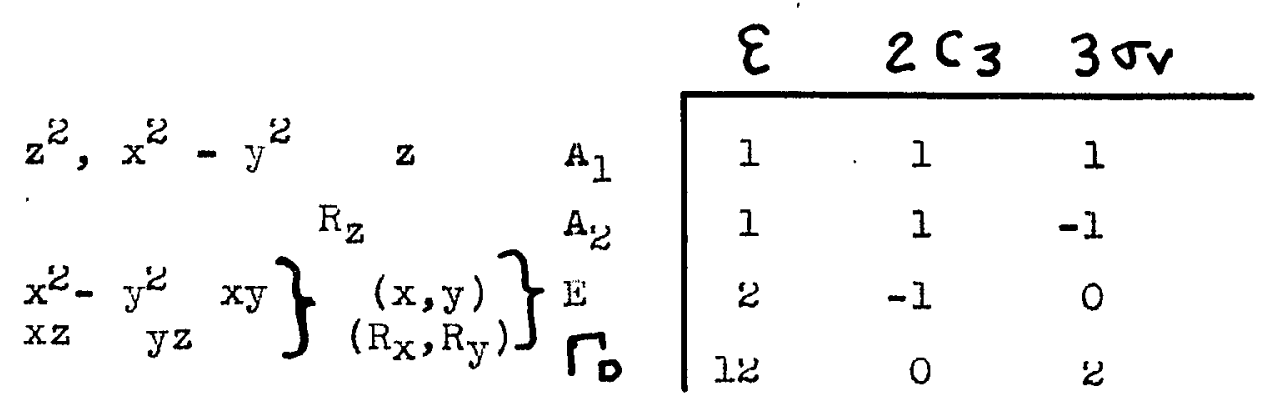


From this we soe that the character for puro translation and rotation is $\Gamma_{t, r}=A_{1}+A_{2}+2 E$; and since $\Gamma_{D}=$ $3 \mathrm{~A}_{1}+\mathrm{A}_{2}+4 \mathrm{E}$, we have remalning for the pure vibration character $\Gamma_{V 1 B^{2}}+2 A_{1}+2 \mathrm{E}$. That is, we shall have six fundamental vibrations (as expected for a four atom nonlinear molecule), but of these two are doubly degenerate, thus only four distinct vibrations appear.

To find the optically active transitions we must remember that they only occur in direct absorption and emission when the transition value of the aipole moment is different from zero, or from the conservation of charee, if we have $\int \Psi_{v}^{*} \cdot x \Psi_{v} d \tau=0$ where the $x$ is one of the body fixed coordinates $x, y$, or $z$. The Raman spectrum appears when integrals of the form $\int \Psi_{v^{\prime}}^{*} x y \Psi_{v} d \tau$ differ from zero. How, if the integrals do have non-zero values, then the integrands must be invariant under all of the group operations, that is they must have craracters which include the totally symmetrje $\mathbb{A}_{1}$ representation. Since we are majnIy concerned with the vibrational fundamentals we first consider integrals of the type $\int \Psi_{0,0,1,0,0,0} x \Psi_{0,0,0,0,0,0} d \tau$. From lage 35 we see that the ground state harmonjc eigenfunctions are completely symetric. For tive first vibrationally excited state the exponential factor, having the transformation properties of a number, will be completely symmetric while the elrst Ilermite polynomial has the symmetry of the nomal coordinate whicl it contains, a fact which is obvious 
when one considers that $H_{I}(x)=2 x$. To check on the possibility or impossibility of a particular transition being optically active one has to multiply together the characters of the three functions forming the integrand of the expectation value integral. If the rosulting character can be expressed as some sum of the characters of the irreducible representations which includes the totally symmetric representation $A_{1}$, then the transition is possible. This, of course, says nothing about the intensity nor does the fact that an absorption is allowed by group theoretical predictions assure that it will actually occur. Eowever, if we ignore rotation-vibration interaction, the reverse situation is a certainty; a Iine forbidden by group theory will not appear.

T'o calculate the allowed transitions for overtones and combination bands the same procedure j.s used only now it is necessary to know the characters of the excited vibrational levels. We know already the characters of the wave functions for $v=0$ and $v=I$, and so those for larger $v^{\prime} \mathrm{s}$ can be found from the following (27):

$$
\begin{aligned}
& \chi_{\vee}(R)=[\chi(R)]^{V} \text { for } f=1 \text { (no degeneracy) } \\
& \left.\chi_{V}(R)=\frac{1}{2}\left[\chi_{v-1}(R) \chi(R)+X_{(R v}\right)\right] \text { for } f=2
\end{aligned}
$$

(27) L. Tisza, ¿. Physik, 82, 48 (1933) 


$$
\begin{gathered}
X_{v}(R)=\frac{1}{3}\left[2 X(R) X_{v-1}(R)-\frac{1}{2} X_{v-2}(R)[X(R)]^{242}\right. \\
\left.+\frac{1}{2} X\left(R^{2}\right) X_{v-2}(R)+X\left(R^{v}\right)\right] \quad \text { for } f=3
\end{gathered}
$$

where $X_{V}(R)$ is the character of the vth simple harmonic oscillator wave function under the operation $R$-- or rather, under the class of' operations of which the group element $R$ is a member. A Iso $X_{0}(R)=I$ and for degenerate levels the value of $v$ is the sum of the $v$ 's going with each eigenfunction of the energy level, that is, $v=\sum_{\alpha=1}^{f} v_{\alpha}$.

From the formulae above, the theorem on the expansion of any characters in terms of the characters of the irreducible representations and the fact that we know the characters for the two lowest $v$ values we can constmat the table following for the $X Y_{3}$ eigenfunctions.

IABLE VI

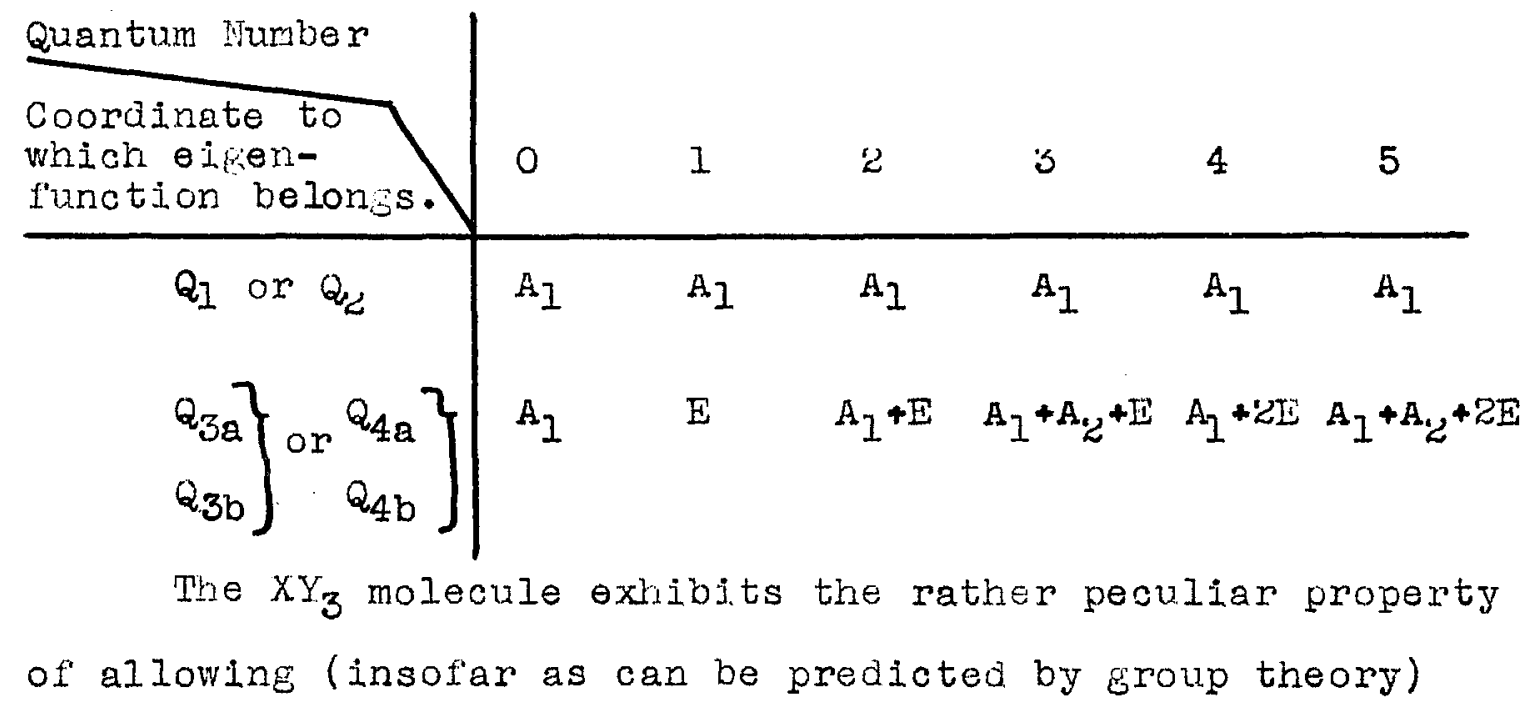


every conceivable transition in both the Raman and the infrared. It was this circumstance, coupled with the relative simplicity of the molecule, which prompted the early Raman investigations on these substances.

Normal Vibrations

From the f'oregoing it can be seen that a fundamental difficulty arises immedately in any at tempt to interpret the observed spectrum of the $X Y_{3}$ in that two of the vibrational fundamentals are doubly degenerate. This means that four of the six generalized force constants degenerate into two pairs of equal constants. What one usually wants, however, is some rather more easily visualized valence force constants. If the molecule is described in terms of bond lengths or bond angles, the transformation to normal coordinates will be by some linear transformation as $\xi_{i}=\sum_{k} a_{i k} x_{k}$, where the $\mathrm{x}_{j}$ are displacements of straightforward nature, such as an increase in bond length or a change in a bond angle. It is generally with respect to displacements such as this that force constants are given. Since the normal coordinates are linearly related to the displacements the potential and kinetic energies are quadratic functions (to the harmonic approximation) of these non-degenerate coordinates (that is, normal coordinates going with non-degenerate vibrations) are only transformed into themselves or into 
their negatives by any of the covering operations which form the group. The degenerate normal coordinates will be transformed among themselves by the same matrices which transformed the degenerate vibrational eigenfunctions (28). When the potential energy is expressed in terms of these normal coordinates, it will be found that no cross terms exist between cooralnates of different symetry species for if there were cross products it would mean that they would change sign under some of the covering operations and this would make the potential energy of the molecule dependent on how the system is viewed. Thus the hamonic potential function for the $X_{i}$ molecule will be, when expressed in normal coordinates (2S):

$$
\begin{array}{r}
2 V=c_{11} \xi_{1}^{2}+2 c_{12} \xi_{1} \xi_{2}+a_{22} \xi_{2}^{2}+c_{33}\left[\xi_{3 a}^{2}+\xi_{3 b}^{2}\right] \\
+2 c_{34}\left[\xi_{3 a} \xi_{4 a}+\xi_{3 b} \xi_{4 b}\right]+c_{44}\left[\xi_{4 a}^{2}+\xi_{4 b}^{2}\right]
\end{array}
$$

and so contain six independent force constants. Since we have but four distinct fundamental frequencies we are forced either to use more equations by measuring isotopic shifts or else to ignore certain of the potential constants.

The letter procejure was that used by Demison (30) who assumed that the restoring forces were only those directed along the interatomic bonds and thus used a potential

(28) Walter, Eyring, and Kimball, op. cit.

(20) T. Y. Wh, Vibration Spectra and Structure of Polyatomic (30) Dolecules, Peking, 
constant of the form

$$
Z V=a_{1}\left[Q_{12}^{2}+Q_{13}^{2}+Q_{14}^{2}\right]+a_{2}\left[Q_{23}^{2}+Q_{24}^{2}+Q_{34}^{2}\right]
$$

where in the $Q_{i j}$ is the change in the length of the $1-j$ bond, the $X$ atom being $\# 1$ and the three $Y$ atoms $\# 2, \# 3$, and $\# 4$. Lechner also assumed a two constant potential of the

form

$$
2 V=a_{1}\left[Q_{12}^{2}+Q_{13}^{2}+Q_{14}^{2}\right]+\alpha_{1} \gamma_{0}^{2}\left[\delta_{23}^{2}+\delta_{24}^{2}+\delta_{34}^{2}\right]
$$

with the $Q_{j j}$ as above and the $\delta_{i j}$ the change in the angle $Y_{1}-X-Y_{j} \cdot r_{0}$ is the equilibrium $X-Y$ distance.

Each of these potential functions gives, when the appropriate secular equation is solved, a quadratic in the square of the frequency. Since there are but two force constants, the four fundamental frequencies are sufficient to determine them twice. Each of these two constant treatments gives the same expression for the angle between the $X-Y$ bond and the symmetry axis of the pyramid (the angle $\beta$ ). It is (31):

$$
\cos ^{2} \beta=\frac{1}{\left[\frac{2 \sigma_{3} \sigma_{4}}{\sigma_{1} \sigma_{2}}\right]^{2}+\frac{3 m-M}{3 m+M}}
$$

(3I) Herzberg, op. cit. 
where $\sigma_{i}$ is the ith fundamental frequency and the masses in the $\mathrm{XY}_{3}$ molecule are $\mathrm{Mm}_{3}$. Figure 8 shows the form of the classical normal vibrations for the $X Y_{3}$ molecule and the notations used here for the various frequencies. Another, more involved, treatment of the $\mathrm{XY}_{3}$ vibration problem was that of Howard and Wilson (32), wo considered a four constant potential function. In this they took account of cross terms between coordinate and angle changes as well as simply chanees themselves, thus:

$$
\begin{aligned}
2 V & =a_{1}\left[Q_{12}^{2}+Q_{13}^{2}+Q_{14}^{2}\right]+2 a_{1}\left[Q_{12} Q_{13}+Q_{13} Q_{14}+Q_{14} Q_{12}\right] \\
& +\alpha_{1} r_{0}^{2}\left[\delta_{23}^{2}+\delta_{24}^{2}+\delta_{34}^{2}\right]+\alpha_{1}^{\prime} r_{0}^{2}\left[\delta_{23} \delta_{24}+\delta_{24} \delta_{34}+\delta_{23} \delta_{34}\right]
\end{aligned}
$$

where the $Q_{i j}$ and the $\delta_{i j}$ are as indjcated above in the potential function of Lechner. This potential olves (s3) the following two quadratios for the four separate frequencies

$$
\begin{aligned}
& m^{2} \lambda^{2}-\left\{\left(a_{1}+2 a_{i}^{\prime}\right) N+\left(\alpha_{1}+2 \alpha_{i}\right) L C\right\} m \lambda+\left(a_{1}+2 a_{i}\right)\left(\alpha_{1}+2 \alpha_{i}\right) \omega \gamma=0 \\
& {\left[m^{2} \lambda^{2}-\left\{\frac{1}{2}\left(a_{1}-a_{i}\right)(c+1)+\left(\alpha_{1}-\alpha_{1}^{\prime}\right) Q \omega\right\} m \lambda+\left(a_{1}-a_{i}\right)\left(\alpha_{1}-\alpha_{i}\right) Q D\right]^{2}=0}
\end{aligned}
$$

(3\%) J. Howard and E. Wilson, op. cit.

(33) cf. Eerzberg, op. cit. 

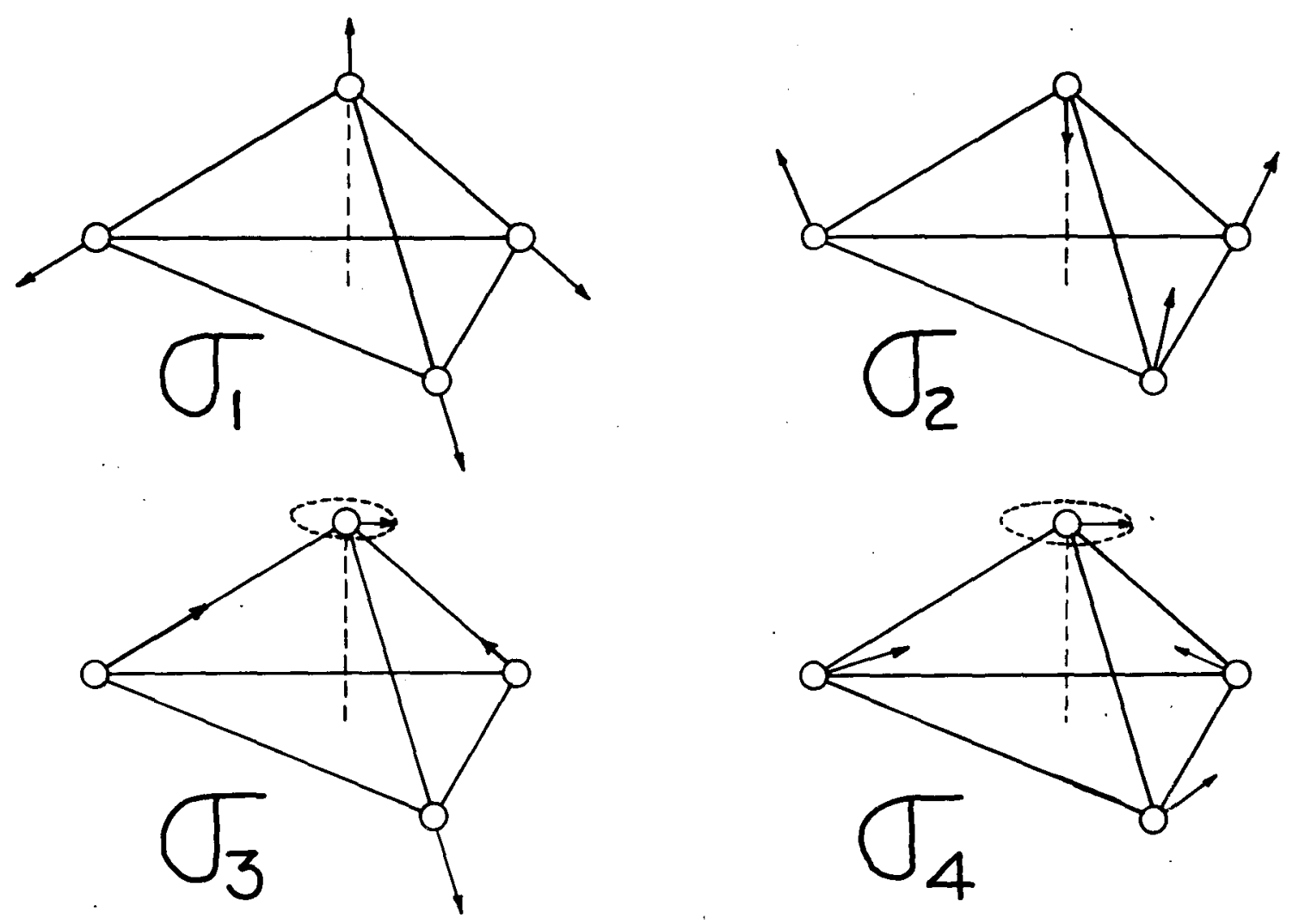

NORMAL VIBRATIONS OF THE $X Y_{3}$ MOLECULE 
where $\lambda_{i}=4 \pi^{2} c^{2} \sigma_{i}^{2} \quad\left(\sigma_{i}\right.$ in $\left.\mathrm{cm}^{-1}\right)$

$$
\begin{array}{ll}
N=\frac{3 m}{M} \cos ^{2} \beta+1 & \gamma=\frac{3 m}{M}+1 \quad L=4 \cos ^{2} \beta \cdot Q \\
C=\frac{3 m}{M} \sin ^{2} \beta+1 & W=\left[\left[\frac{3 m}{2 M}\right] \sin ^{2} \beta-1\right] \sin ^{2} \beta+2 \\
Q=\frac{3}{4-3 \sin ^{2} \beta} & D=\left[\frac{3 m}{M}-1\right] \sin ^{2} \beta+2
\end{array}
$$

In order to obtain the potential constants from the frequencies the above quadratics must be turned inside out and this yielas two quadratics in two linear combinations of two of the force constants and these may then be solved to give the constants themselves. Thus

$$
\begin{aligned}
& {\left[\alpha_{1}+2 \alpha_{i}\right]^{2} L^{2} C \gamma-\left[\alpha_{1}+2 \alpha_{i}\right] \omega \gamma\left[\lambda_{1}+\lambda_{2}\right] m+m^{2} \lambda_{1} \lambda_{2} N=0} \\
& {\left[\alpha_{i}-\alpha_{1}\right]^{2} 2 Q^{2} D \omega-\left[\alpha_{1}-\alpha_{i}\right] 2 Q D m\left[\lambda_{3}+\lambda_{4}\right]+[c+1] \lambda_{3} \lambda_{4} m^{2}=0}
\end{aligned}
$$

Finally one must solve for the other two force constants, but this is easily done, for

$$
a_{1}+2 a_{1}^{\prime}=\frac{m^{2} \lambda_{1} \lambda_{2}}{\left(\alpha_{1}+2 \alpha_{i}\right) L \gamma} \quad a_{1}-a_{1}^{\prime}=\frac{m^{2} \lambda_{3} \lambda_{4}}{\left(\alpha_{1}-\alpha_{i}^{\prime}\right) Q D}
$$

Howard and ilson applied this to some early Raman data. The method gives certainly very reasonable results when used with the present infrared measurements -- although it was necessary to change some of the earlier assignments in $\mathrm{SbCl}_{3}$ and some of the derived force constants (especially the cross terms) are greatly different from the ones obtained from Raman data.

Rosonthal, in a series of parers, treated the molecules 
on the basis of the most general six constant potential functions (34). If we apuin assume the peak atom to be \#I and the three $Y$ atoms to be $\# 2, \# 3$, and $\ddot{\# 4}$, the potential function considers changes in bond lengths and is $2 v=a_{\{}\left[Q_{12}^{2}+Q_{13}^{2}+Q_{14}^{2}\right]+2 a_{i}\left[Q_{12} Q_{13}+Q_{13} Q_{14}+Q_{14} Q_{12}\right]$ $+a_{2}\left[Q_{23}^{2}+Q_{24}^{2}+Q_{34}^{2}\right]+2 a_{2}^{\prime}\left[Q_{23} Q_{24}+Q_{24} Q_{34}+Q_{23} Q_{34}\right]$ $+2 a_{3}\left[Q_{12} Q_{34}+Q_{13} Q_{24}+Q_{14} Q_{23}\right]+a_{4}\left[Q_{34}\left[Q_{13}+Q_{14}\right]+Q_{24}\left[Q_{12}+Q_{14}\right]+Q_{23}\left[Q_{12}+Z_{13}\right]\right)$ This gigain yields a quadratic in the frequencies but one containing all the six possible constants geometrically permitted for a harmonic potential function and thus is of no use unless we have isotopic molecules to work with; in which case a number of very interesting relationships can be derived.

It happens that of the five atoms with which we are dealins trree are doubly isotopic. The relative abundance of the chlorine isotopes are $3: 1$, and the two isotopes of bromine and antimony appear in nearly equal amounts. That this will lead to a considerable number of isotopic molecular hybrids is apparent from the following. Consider the atomic masses as $\mathrm{H}_{\mathrm{i}} \mathrm{g}^{\prime}, \mathrm{m}$ and $\mathrm{m}^{\prime}$, the molecule being $\mathrm{Nm}_{3}$. If we denote by $P(M), F\left(M^{r}\right), P(m)$ and $P\left(m^{l}\right)$, the fraction of each isotope appearing, we shall have these abundances for

(34) J. Rosenthal, op. cit. 
the molecules:

TABLE VII

\begin{tabular}{|c|c|c|c|}
\hline $\mathrm{Mm}_{3}$ & $P(N)(P(m))^{3}$ & $\mathrm{M}^{\prime} \mathrm{m}_{3}$ & $P(M !)(P(m))^{3}$ \\
\hline $\mathrm{Mm}_{2} \mathrm{~m}^{\prime}$ & $3 P(N) P\left(m^{\prime}\right)(P(m))^{2}$ & $\mathrm{~N}^{\prime} \mathrm{m}_{\mathrm{z}^{\prime}} \mathrm{m}^{\prime} ;$ & $3 P\left(M^{\prime}\right) P\left(m^{\prime}\right)(P(m))^{2}$ \\
\hline Mmmá; & $3 P(N)\left(P\left(m^{1}\right)\right)^{2} P(m)$ & I'mm; & $3 P\left(m^{\prime}\right)\left(P\left(m^{\prime}\right)\right)^{2} p(m)$ \\
\hline $\operatorname{Mm} \frac{1}{3} ;$ & $P(N)\left(F\left(m^{\prime}\right)\right)^{3}$ & $M^{\prime} m_{3}^{\prime}$ & $P\left(n^{\prime}\right)\left(P\left(m^{\prime}\right)\right)^{3}$ \\
\hline
\end{tabular}

Whence, as will be seen for $\mathrm{SbBr}_{3}$ especially, we can have a large number of various kinds of hybrid molecules. These hybrids are not of the $X Y_{3}$ type at all except insofiar as the potential energies are concerned -- since we assume that the force constants do not change when an isotopic substitution is mae. This situation too was considered by Rosenthal and Salant (35) on the basis of the most general six-constant potential function. If one considers $\sigma_{1}, \sigma_{2}, \sigma_{3}$ and $\sigma_{4}$ to be the four fundamental frequencies for the $\mathrm{Nm}_{3}$ molecule and if we take $M$ and $m$ to bo the changes in mass upon boing to another isotope (where $\frac{\delta M}{M}$ and $\frac{\delta m}{m} \ll<$ ) we shall have the following relations amongst the frequency shifts:

$$
\text { For inm.g to } \pi m_{c}(m+\delta m)
$$$$
\text { paraliel froquencies; } \frac{\delta \sigma_{1}}{\sigma_{1}}+\frac{\delta \sigma_{2}}{\sigma_{2}}=-\frac{\left[\frac{\mu}{m}+1\right] \delta m}{2(3 m+\delta m)}
$$

(35) J. Rosenthul and E. Salant, op. cit. 
perpendicular frequencies;

$$
\frac{\delta \sigma_{3}}{\sigma_{3}}+\frac{\delta \sigma_{4}}{\sigma_{4}}=-\frac{\delta m}{6 m}\left[\frac{\frac{\mu}{m}-2}{b}+3\right] \frac{\delta \sigma_{5}}{\sigma_{5}}+\frac{\delta \sigma_{6}}{\sigma_{6}}=-\frac{\delta m}{6 m}\left[\frac{\mu}{m b}+1\right]
$$

where $b=1+\frac{2 \mu}{m} \cot ^{2} \beta$ and $\mu=\frac{m M}{M+3 m}$

It should be noted that the symmetry which is lost in hybridizing the molecule removes the degeneracy in the two perpendicular frequencies 30 that, while $\sigma_{3}=\sigma_{5}$ and $\sigma_{4}=\sigma_{6}$, $\delta \sigma_{3} \neq \delta \sigma_{5}$ and $\delta \sigma_{4} \neq \delta \sigma_{6}$

For the case that the $X$ atom is replaced, we have

$$
\frac{\delta \sigma_{1}}{\sigma_{1}}+\frac{\delta \sigma_{2}}{\sigma_{2}}=\frac{\left(\frac{\mu}{m}-1\right) \delta M}{2(M+\delta M)} \text { and } \frac{\delta \sigma_{3}}{\sigma_{3}}+\frac{\delta \sigma_{4}}{\sigma_{4}}=\frac{\left(\frac{\mu}{m}-1\right) \delta M}{2 b(M+\delta M)}
$$

this substitution leaving the symmetry as before.

For the case of the isotopic molecule $\lim _{3}^{\prime}$ there is an exact (i.e., not dependent on $\delta m<<m$ ) relationship between the original and displaced frequencies, it is:

$$
\left[\frac{\sigma_{1}^{\prime} \sigma_{2}^{\prime}}{\sigma_{1} \sigma_{2}}\right]^{2}=\frac{m \mu}{m^{\prime} \mu^{\prime}},\left[\frac{\sigma_{3}^{\prime} \sigma_{4}^{\prime}}{\sigma_{3} \sigma_{4}}\right]^{2}=\frac{b^{\prime} m \mu}{b m^{\prime} \mu^{\prime}} \text { where } \sigma_{i}^{\prime}=\sigma_{i}+\delta \sigma_{i}
$$

Note that this latter expression can also be used to calculate the shift for a replacement $n$ to $M+\delta M$ and indeed these two last expressions are equivalent if one assumes $\frac{\delta M}{M}$ to be very small and $s m+M x \cdot s m+M^{\prime}$. The f'our constant Howard and wilson potential function gives the same expression for the frequency product ratios as does Rosenthal's. 
The actual magnitude of the frequency shifts for isotopic substitutions which leave the $C_{5 \mathrm{v}}$ symmetry cannot bo obtained without knowing the potential constants involved. we can calculate these shifts on the basis of the HowardWilson potential function frequency expressions in the follow lng manner;

If we put

$$
\begin{array}{ll}
A=\alpha_{1}+2 \alpha_{1} & Q=\alpha_{1}-\alpha_{1} \\
B=\alpha_{1}+2 \alpha_{1} & B=\alpha_{1}-\alpha_{1}
\end{array}
$$

then we have for the roots of the secular equations (seo Page 46):

$$
\lambda_{1}+\lambda_{2}=\frac{A N+B \omega C}{m} \quad \lambda_{3}+\lambda_{4}=\frac{\frac{1}{2} Q[c+1]+B Q \omega}{m}
$$

$$
\lambda_{1} \lambda_{2}=\frac{A B \omega \gamma}{m^{2}} \quad \lambda_{3} \lambda_{4}=\frac{Q B Q D}{m^{2}}
$$

If now we take the variation of the expressions and solve them simultuneously between the two expressions for the same type of frequency, we shall obtain expressions for the $a b-$ solute magnitude of the isotopic frequency shifts, thus:

$$
\delta \lambda_{1}=-\lambda_{1} \frac{\delta m}{m}+\frac{\lambda_{1}[A \delta N+B \omega \delta c]}{m\left(\lambda_{1}-\lambda_{2}\right)}-\frac{A B \omega \delta \gamma}{m^{2}\left(\lambda_{1}-\lambda_{2}\right)}
$$

or returning to the original notation and writing the frequencies in reciprocal centimeters. 


$$
\delta \sigma_{1}=-\frac{\delta m}{2 m} \sigma_{1}+\frac{[A \delta N+B \omega \delta c] \sigma_{1}}{8 \pi^{2} c^{2} m\left[\sigma_{1}^{2}-\sigma_{2}^{2}\right]}-\frac{2 A B \omega \delta \gamma}{\left[8 \pi^{2} c^{2} m\right]^{2}\left[\sigma_{1}^{2}-\sigma_{2}^{2}\right] \sigma_{1}}
$$

$$
\delta \sigma_{3}=-\frac{\delta m}{2 m} \sigma_{3}+\frac{\left[\frac{1}{2} Q \delta c+B Q \delta \omega\right] \sigma_{3}}{8 \pi^{2} c^{2} m\left[\sigma_{3}^{2}-\sigma_{4}^{2}\right]}-\frac{2 Q Q Q \delta D}{\left[8 \pi^{2} c^{2} m\right]^{2}\left[\sigma_{3}^{2}-\sigma_{4}^{2}\right] \sigma_{3}}
$$

The value of the displacement of the other fundamental erequency in each of the puirs being given by the sume expression with the subscripts reversed -- thus replace 1 by 2 and $z$ by 1 , and 3 by 4 and 4 by 3 . These are valid only for isotopic replacoments which do not disturb the symmetry as $H \rightarrow+\delta$ or lor al 1 three $Y$ atoms of mass $m$ being replaced by three atoms of $m+\delta m$.

If we form sums of these expressjons similar to those on Page 51, we again obtain those given there (to the approximation $N+\delta \mathrm{N}$ ) whlle for the isotopic displacement of the frequencies with the substitution $\mathrm{im}_{3} \rightarrow \mathrm{N}(\mathrm{m}+\delta \mathrm{m})_{3}$, we Eet

$$
\frac{\delta \sigma_{1}}{\sigma_{1}}+\frac{\delta \sigma_{2}}{\sigma_{2}}=-\frac{\delta m}{2 m}\left[\frac{\mu}{m}+1\right], \frac{\delta \sigma_{3}}{\sigma_{3}}+\frac{\delta \sigma_{4}}{\sigma_{4}}=-\frac{\delta m}{2 m}\left[\frac{\mu}{b}-1\right]
$$

Finally, making use of the first of these expressions and the Rosenthal formula for the $M m_{3}$ to $M(m+\delta m) m_{*}$ replacement we can get an expression for the substitution $i l m_{5} \rightarrow M(m+\delta m) \cdot{ }_{2}$. 
54

It is

$$
\frac{\delta \sigma_{1}}{\sigma_{1}}+\frac{\delta \sigma_{2}}{\sigma_{2}}=-\frac{\delta m}{3 m}\left[\frac{\mu}{m}+1\right]
$$

The same procedure dives for the perpendicular bands,

$$
\begin{aligned}
& \frac{\delta \sigma_{3}}{\sigma_{3}}+\frac{\delta \sigma_{4}}{\sigma_{4}}=-\frac{\delta m}{6 m}\left[\frac{\frac{2 \mu}{m}-1}{b}+3\right] \\
& \frac{\delta \sigma_{5}}{\sigma_{5}}+\frac{\delta \sigma_{6}}{\sigma_{6}}=-\frac{\delta m}{6 m}\left[\frac{\frac{2 \mu}{m}-3}{b}+5\right]
\end{aligned}
$$




\section{EXPERIIE NTAL RESULTS}

\section{(1) Phosphorus Trichloride}

The $\mathrm{PCl}_{3}$ used was Mallinckrodt C.P. obtained commercially and no attempt was made to purify it further. It is a clear I1quid with an extremely pungent odor. It is also a violent poison, lurgely because it will react with water to produce ECI and $\mathrm{H}_{3} \mathrm{FO}_{5}$, the latter especially, like most phosphorus compounds, being extremely dangerous. Kohlrausch (36) gives the Raman determined frequencies as:

TABLE VIII

$$
\begin{aligned}
& \sigma_{1}=510 \mathrm{~cm}^{-1} \\
& \sigma_{2}=257 \mathrm{~cm}^{-1} \\
& \sigma_{3}=480 \mathrm{~cm}^{-1} \\
& \sigma_{4}=190 \mathrm{~cm}^{-1}
\end{aligned}
$$

with no estimate of probable accuracy.

$$
\text { Brockway (37), on the basis of electron diffraction }
$$
measurements, gives an $X-Y$ distance of $\% .00 \mathrm{~A}$ and an $X-Y-X$ angle of $101^{\circ}\left(\beta=64^{\circ}\right)$. The best microwave measurements (s8) yield $\beta=62^{\circ} 15^{\prime}$, however, and this smaller value will

(36) Kohlrausch, op. oit., p. 144. (37) Brockway, op cit.

(38) Gordy, Smith, and Trambarulo, op. cit. 
be used in the calculations contained in this report.

The cell was filled as previously described, all of the manipulations being carried out under a hood. This precaution, as well as such others as the wearing of gloves and gogsles, is absolutely necessary. The vapor pressure of the liquid is $15 \mathrm{~cm}$ of $\mathrm{Fg}$ and the air in a closed room will become impossible to breathe a few minutes afte: a bottle of it is opened to the air. After the cell was filled, it was Immediately taken to the spectrometer, the windows of the cell were sluiced off with methyl alcohol, and the cell was placed in the evacuable chamber which was then exhausted. It is necessary to exercise extreme caution in filling the cell since any of the $\mathrm{PCl}_{5}$ which happens to slop onto the outside of the cell windows will soon spread out and produce a precipitate which scatters the radiation rather badly. The alcohol removes this, but after the cleaning the cell should be put into a vacuum as quickly as possible. If the cell is left in the air for any more than a few minvtes, enough of the $\mathrm{PCl}_{3}$ will soak through the polyethylene window to react with the water vapor in the ai $r$ to produce the same precipitate. The PCI.s will eventually attack the Koroseal spacer and cause it to harden und crack and so leak. This Koroseal reaction usually requires several hours, however, und so is not of much consequence.

The procedure used in measuring the spectry of this and of the other liquids was to run the spectrometer through 
the wavelength region under investigation, first with the cell empty and then with the cell filled with the liquid. This comparison with the empty cell was made partly to form an estimate of the relative intensities of the different frequencies and partly to assure accuracy in locating the line position, since the intensity of the radiation background chunges quite rapialy with frequency in some of the regions.

In making assienments it was assumed initially that the Raman investigators were correct. Woreover, by compurison with the other $X Y_{3}$ molecules having fundamentals in the near infrared, it can be seen that the following rules will be generaliy applicable ( (39):

1) Frequencywise (in the notation of Figure 8): $\sigma_{4}<\sigma_{2}<\sigma_{3}$

z) The intensity of $\sigma_{35}$ is sreater than that of $\sigma_{1}$.

3) Also, $\sigma_{1}$ is usially larger than $\sigma_{3}$.

4) $\sigma_{i}$ and $\sigma_{4}$ are both bending modes and it is quite reasonable to expect them to have the lowest frequencies.

The spectrum obtained is shown in Figure 9 , the path lengths being, neelecting a probable residual ten-percent buluing of the cell windows, l.z millimeters for all of the runs except the supplomentary measurement on the $\sigma_{1}$ absorption. This was obtained usine a thloker spacer composed of

(39) M. K. Wilson, op. cit. 

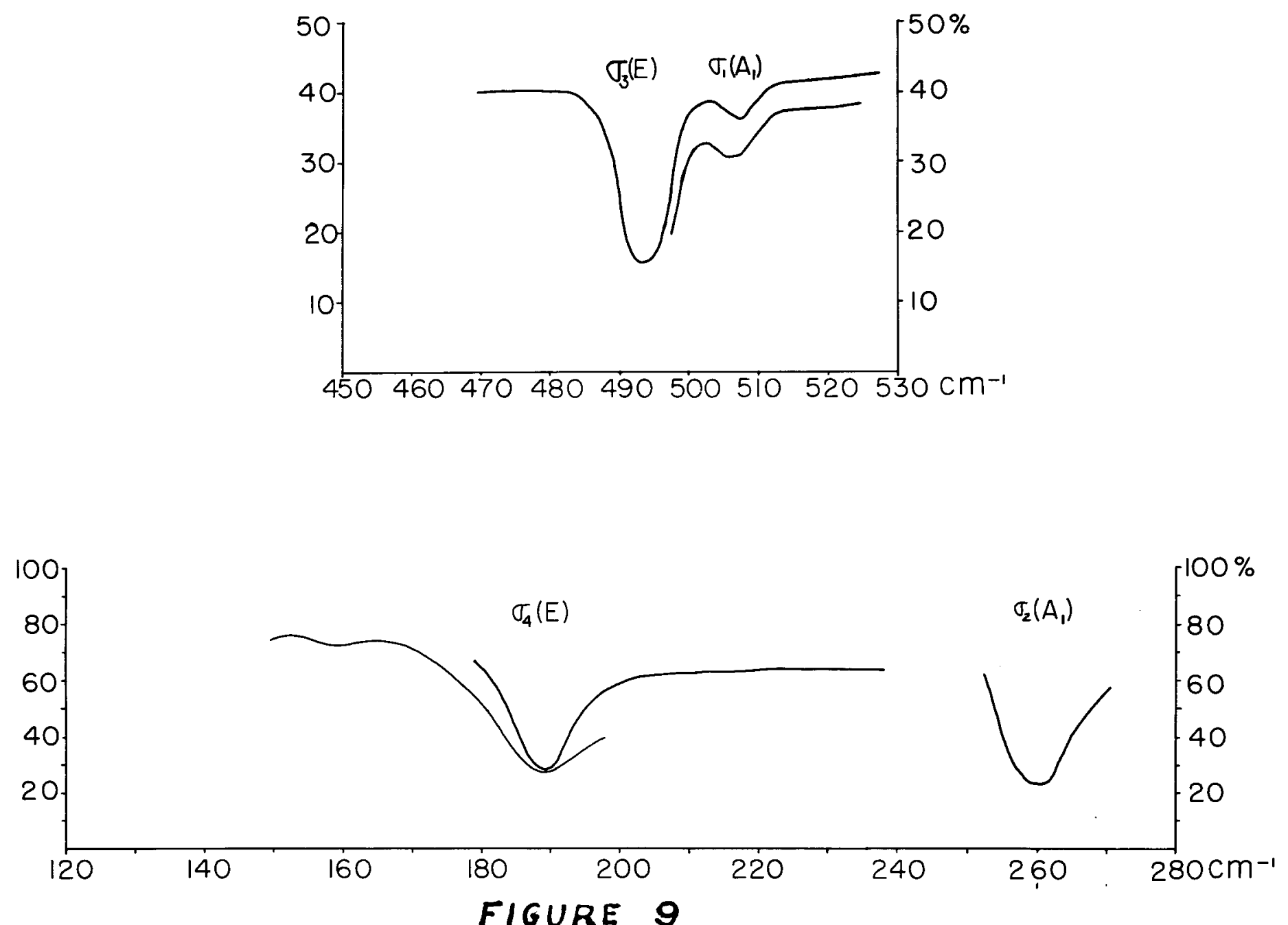

FAR INFRARED SPECTRUM OF $\mathrm{PCI}_{3}$ 
Koroseal and $0.010^{\prime \prime}$ polyethylene clamped together and thus represents a path length of approximately $1.5 \mathrm{~mm}$. millimeters. The assignments are imrsediately obtained from the rules of thumb indicated above and agree with the Raman assignments as well as elving quite acceptable force constants. The principal factor limiting the accuracy of locations of the Iine centers was the fact that the absorptions when measured with the substance in tlis plase are quite broad,

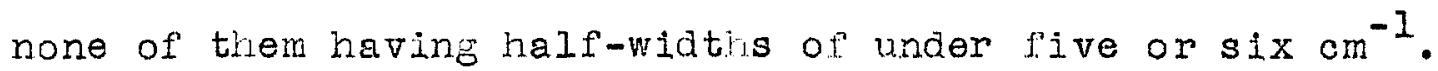
The errors inherent in the instrument itself have al ready been discussed in the section of this repo rt dealing with experimental techniques, and these introduce much less uncertainty than that caused by the broud width of the Iine. The measured vibratiunal fundamentals, then, to the accuracy possible, are

$$
\begin{aligned}
& \sigma_{1}=507.4 \pm 0.5 \mathrm{~cm}^{-1} \\
& \sigma_{2}=260.1 \pm 0.2 \mathrm{~cm}^{-1} \\
& \sigma_{3}=493.5 \pm 0.5 \mathrm{~cm}^{-1} \\
& \sigma_{4}=189.0 \pm 0.3 \mathrm{~cm}^{-1}
\end{aligned}
$$

The constants usei in the reduction of the data are given in the following table alone with the force constants of the four constant potential function given in the Theoretical section. The angle $\beta$ is that indicated above and the distance $r$ is the $X-Y$ distance in the molecule, obtained from the microwave determination of the $B$ value of 
the molecule (40).

TABLE IX

$$
\begin{array}{rlrl}
\beta & =62^{\circ} 151 & a_{1}=21.72 \times 10^{4} \mathrm{dynes} / \mathrm{cm} \\
M_{P}=30.98 \mathrm{amu} & a_{1}=0.933 \times 10^{4} \mathrm{dynes} / \mathrm{cm} \\
M_{C 1}=34.98 \mathrm{amu}(75 \%) & \alpha_{1}=3.195 \times 10^{4} \mathrm{dynes} / \mathrm{cm} \\
M_{C I}^{\prime}=36.98 \mathrm{amu}(25 \%) & \alpha_{1}=0.672 \times 10^{4} \mathrm{dynes} / \mathrm{cm} \\
1 \mathrm{amu}=1.6604 \times 10^{-24} \mathrm{gms} . & \\
c & =2.998 \times 10^{10} \mathrm{~cm} / \mathrm{sec} & \\
r_{0}-2.043 \times 10^{-8} \mathrm{~cm} & &
\end{array}
$$

No aifficulty was experienced in calculating the constants and, as an arithmetical check, the frequencies were recalculated from the force constants. The frequencies were all with $0.1 \%$ of their observed values.

From the percentages of the naturally occurring isotopes of phosphorus and chiorine given in the above table, the percentages of the various hybrids of $\mathrm{FCl}_{3}$ which will be present in a random mixture are:

$$
\begin{array}{lr}
\mathrm{F}^{31} \mathrm{Cl}_{3}^{35} & 42.1 \% \\
\mathrm{P}_{31}^{51} \mathrm{Cl}_{35}^{35} \mathrm{Cl}^{37} & 42.1 \% \\
\mathrm{P}^{31} \mathrm{Cl}_{\mathrm{Cl}}^{37} & 14.0 \% \\
\mathrm{P}^{31} \mathrm{Cl}_{3}^{37} & 1.6 \%
\end{array}
$$

(40) Gordy, op. cit. 
From this it is evident that the two molecules which will contribute most significantly to the absorptions are the purebred $\mathrm{P}^{31_{\mathrm{Cl}}} \mathrm{S}_{\mathrm{S}}^{35}$ and the hybrid $\mathrm{P}^{31_{\mathrm{Cl}}}{ }_{\mathrm{L}}^{35} \mathrm{Cl}{ }^{37}$.

Using the atomic masses gilven above in Table IX, we obtain the sum relationships of the isotopic frequency shifts as discussed in the Theoretical Section.

For the parallel bands

$$
\frac{\delta \sigma_{1}}{507.4}+\frac{\delta \sigma_{2}}{260.1}=-0.01148
$$

and for the perpendicular bands

$$
\begin{aligned}
& \frac{\delta \sigma_{3}}{493.5}+\frac{\delta \sigma_{4}}{189.0}=-0.0136 \\
& \frac{\delta \sigma_{5}}{493.5}+\frac{\delta \sigma_{6}}{189.0}=-0.0115
\end{aligned}
$$

Values which can be satisfied by the shifts

$$
\begin{aligned}
& \delta \sigma_{1}=-2.3 \mathrm{~cm}^{-1} \\
& \delta \sigma_{2}=-1.5 \mathrm{~cm}^{-1} \\
& \delta \sigma_{3}=-2.0 \mathrm{~cm}^{-1} \\
& \delta \sigma_{4}=-1.5 \mathrm{~cm}^{-1}
\end{aligned}
$$

and these are we.11 within the displacements compatible with the Iine shapes in Figure 9. 
(2) Arsenic Trichlorido

$\mathrm{AsCl}_{3}$ is quite similar to $\mathrm{PCl}_{3}$ chemically and the methods used in obtaining its spectrum are also much like those employed with the phosphorus halide. Commercially obtained Nallinckrodt C.F. $\mathrm{ASCl}_{3}$ was used in the Ilquid cell described above. The only major difference was that it was necessary to use a thinner liquid sample so that in place of the Koroseal spacer a 0.010" spacer of polyethylene was used. This was smeared with Silicone Vacuum Wax in order to make a 11quid-tight seal. The precautions about cleaning the outside of the cell are also to be observed here as well as the safety measures, although the lower vapor pressure of this liquid (2.6 $\mathrm{mm} \mathrm{Hg}$ ) makes it a good deal easier to work with.

Kohlrausch ives the Raman frequencjes as

$$
\begin{gathered}
\text { TARLE } X \\
\sigma_{1}=410 \mathrm{~cm}^{-1} \\
\sigma_{2}=195 \mathrm{~cm}^{-1} \\
\sigma_{3}=370 \mathrm{~cm}^{-1} \\
\sigma_{4}=159 \mathrm{~cm}^{-1}
\end{gathered}
$$

with no estimate of probable accuracy.

Brockway's electron diffraction measurements are $2.16 \mathrm{~A}$ for the $X-Y$ distance and $103^{\circ}$ for the $X-Y-X$ ande $\left(\beta=64^{\circ}\right)$. The microwave data gjve 61001' for $\beta$ and this value will be used in the calculations. 
Figure 10 shows the experimental results obtained for $\mathrm{AsC}_{3} \cdot \mathrm{C}$ The absorptions for the $\sigma_{2}$ and $\sigma_{4}$ vibrations were obtained with the $0.010 "(0.4 \mathrm{~mm})$ spacer and also with the Troroseal spacer. The $\sigma_{1}$ and $\sigma_{3}$ vibrations were measured using the cell with the Koroseal spacer and the supplementary $\sigma_{3}$ mun was made by soaking polyethylene overnight in $\mathrm{AsCl}_{3}$ and then measuring the spectrum of the soaked sheet. This latter method was followed for the $\sigma_{3}$ absorption because its strength was such as to make difilcult good frequency determinations in any liquid thickness possible with this cell. The measured vibrational fundamentals are

$$
\begin{aligned}
& \sigma_{1}=411.8 \pm 1.0 \mathrm{~cm}^{-1} \\
& \sigma_{2}=193.6 \pm 0.5 \mathrm{~cm}^{-1} \\
& \sigma_{3}=386.7 \pm 0.5 \mathrm{~cm}^{-1} \\
& \sigma_{4}=155.3 \pm 0.7 \mathrm{~cm}^{-1}
\end{aligned}
$$

and the following table gives the constants used in the calculations as well as the calculated force constants. There were no difficulties encountered in the calculation of the force constants and an arithmetical recheck showed them to fit the data to within the probable error. The value of $r_{0}$ is taken from the microwave data reported in Gordy (4I).

(41) Gordy, smith, and Trambarulo, op. cit. 

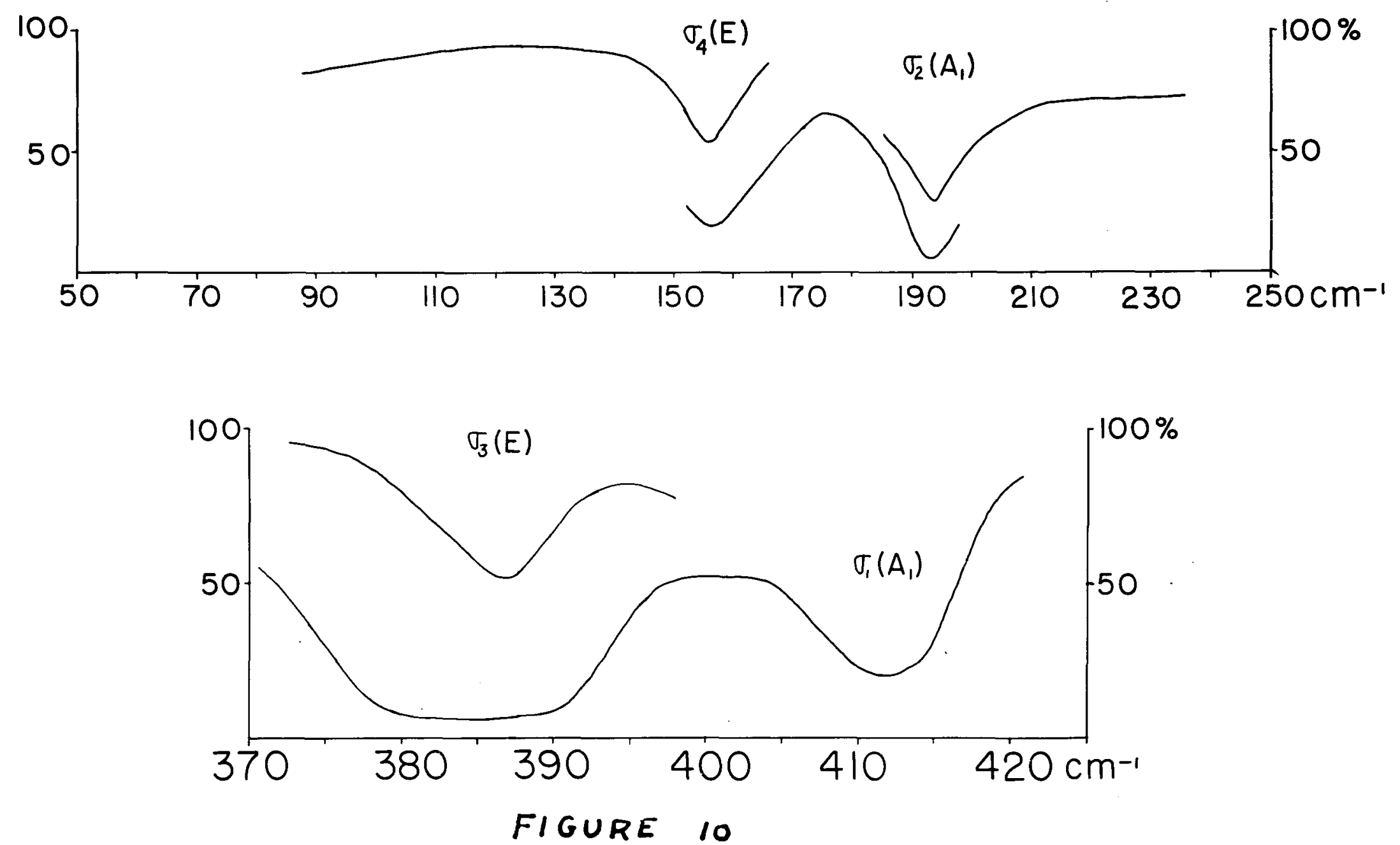

FAR INFRARED SPECTRUM OF As $\mathrm{Cl}_{3}$ 
TABIE XI

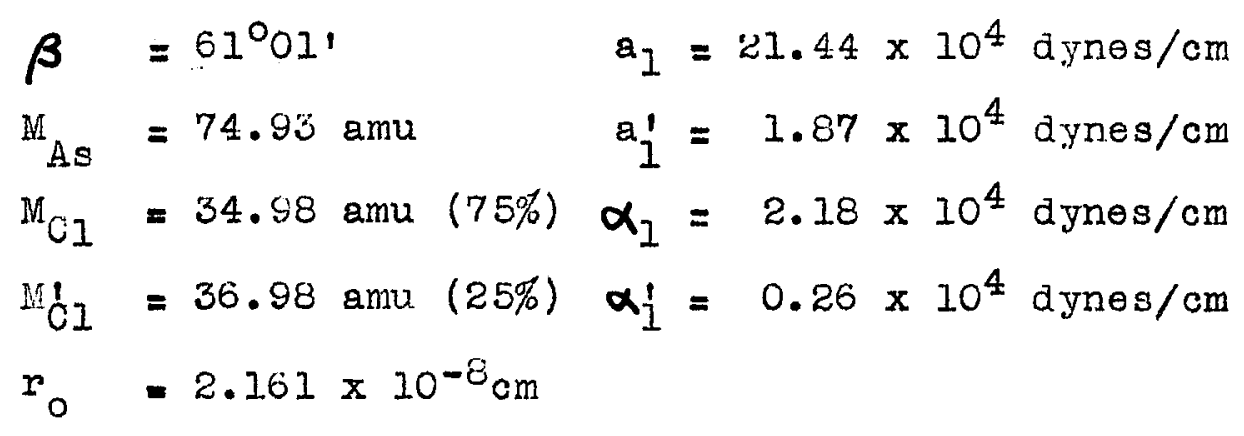

The percentages of the various molecular hybrids will be just as for $\mathrm{PCI}_{3}$, that is

$$
\begin{aligned}
& \mathrm{As}^{75} \mathrm{Cl}_{3}^{35} \quad 42.1 \% \\
& \mathrm{As}^{75} \mathrm{Cl}_{2}^{35} \mathrm{Cl}{ }^{37} \quad 42.1 \% \\
& \mathrm{As}^{75} \mathrm{Cl} 35_{\mathrm{Cl}}^{37} \quad 14.0 \% \\
& \mathrm{As}^{75} \mathrm{CI}_{3}^{37} \quad 1.6 \%
\end{aligned}
$$

and only the two most abundant molecules will be considered here. Using the atomic masses given above, we find, for the parallel bands

$$
\frac{\delta \sigma_{1}}{\sigma_{1}}+\frac{\delta \sigma_{2}}{\sigma_{2}}=-0.013
$$

and for the perpendiculur bands

$$
\begin{aligned}
& \frac{\delta \sigma_{3}}{\sigma_{3}}+\frac{\delta \sigma_{4}}{\sigma_{4}}=-0.017 \\
& \frac{\delta \sigma_{5}}{\sigma_{5}}+\frac{\delta \sigma_{6}}{\sigma_{6}}=-0.013
\end{aligned}
$$

Valees which can be satisfied by the shif'ts

$$
\begin{array}{ll}
\delta \sigma_{1}=-2.0 \mathrm{~cm}^{-1} & \delta \sigma_{2}=-1.5 \mathrm{~cm}^{-1} \\
\delta \sigma_{3}=-2.0 \mathrm{~cm}^{-1} & \delta \sigma_{4}=-1.3 \mathrm{~cm}^{-1}
\end{array}
$$


which, again, are in agreement with the line shapes (Figure 10).

\section{(3) Phosphorus Tribromide}

This is the most dificult to handle of the substances investigated. It fumes violently when exposed to air, and attacks all of the common waxes so that it is impossible to store it for any lenth of time after once opening the glass sealed bottle in which it is obtained commercially. Its vapor pressure is $6.4 \mathrm{~cm} \mathrm{Hg}$, and it was handed in exactly the same fashion as the $\mathrm{PCl}_{3}$ treated above.

The Raman frequencies from Kohlrausch are

$$
\begin{aligned}
& \text { TABIE XII } \\
& \sigma_{1}=380 \mathrm{~cm}^{-1} \\
& \sigma_{2}=162 \mathrm{~cm}^{-1} \\
& \sigma_{3}=400 \mathrm{~cm}^{-1} \\
& \sigma_{4}=116 \mathrm{~cm}^{-1}
\end{aligned}
$$

and the only value for the angle discovered in the literature was that of Pauling (42), who gives $100^{\circ}$ for the $5 r-$ P-Br angle, or $\beta=62^{\circ} 12^{\prime}$. This value, however, leacs to immediate difficulties in that we obtain imacinary force constants.

(42) L. Pauling, 으. it. 
As may be seen from the theoretical section above, it must be that, using the Foward and Wilson potential function, in order to have real force constants

$$
\frac{\left[\lambda_{1}+\lambda_{2}\right]^{2}}{\lambda_{1} \lambda_{2}} \geqslant \frac{4 N C}{r}
$$

or upon substitution and reduction

$$
\frac{\left(\lambda_{1}-\lambda_{2}\right) M}{6 m} \sqrt{\frac{\gamma}{\lambda_{1} \lambda_{2}}} \geqslant \sin \beta \cos \beta
$$

It is assumed that in Figure $11, \sigma_{1}$ and $\sigma_{3}$ must lie so close together that they cannot be resolved as separate lines. The spectra in Figure 11 are from runs made with the $1 . *$ millimeter ceIl except for the supplementary mun from s\&O $\mathrm{cm}^{-1}$ to $400 \mathrm{~cm}^{-1}$, which was made using the above-mentioned method of soaking the polyethylene in the liquid PBr. Also a search was made from $340 \mathrm{~cm}^{-1}$ to $460 \mathrm{~cm}^{-1}$ to attempt to locate $\sigma_{1}$ separate from $\sigma_{3^{*}}$ As a consequence of the fact that $\sigma_{1}$ is overlain by $\sigma_{3}$, the position of $\sigma_{1}$ is in doubt by some $10 \mathrm{~cm}^{-1}$; this presumes that the intensity of $\sigma_{3}$ is much larger than that of $\sigma_{1}$, which is the case for the other molecules studied. The measured vibrational frequencies are, therefore

$$
\begin{aligned}
& \sigma_{1}=392 \pm 5 \mathrm{~cm}^{-1} \\
& \sigma_{2}=161.5 \pm 0.5 \mathrm{~cm}^{-1} \\
& \sigma_{3}=392.2 \pm 0.5 \mathrm{~cm}^{-1} \\
& \sigma_{4}=115.7 \pm 0.7 \mathrm{~cm}^{-1}
\end{aligned}
$$

Using the relationships given above we can derive the restrictions on the bond angle corresponding to the extreme 

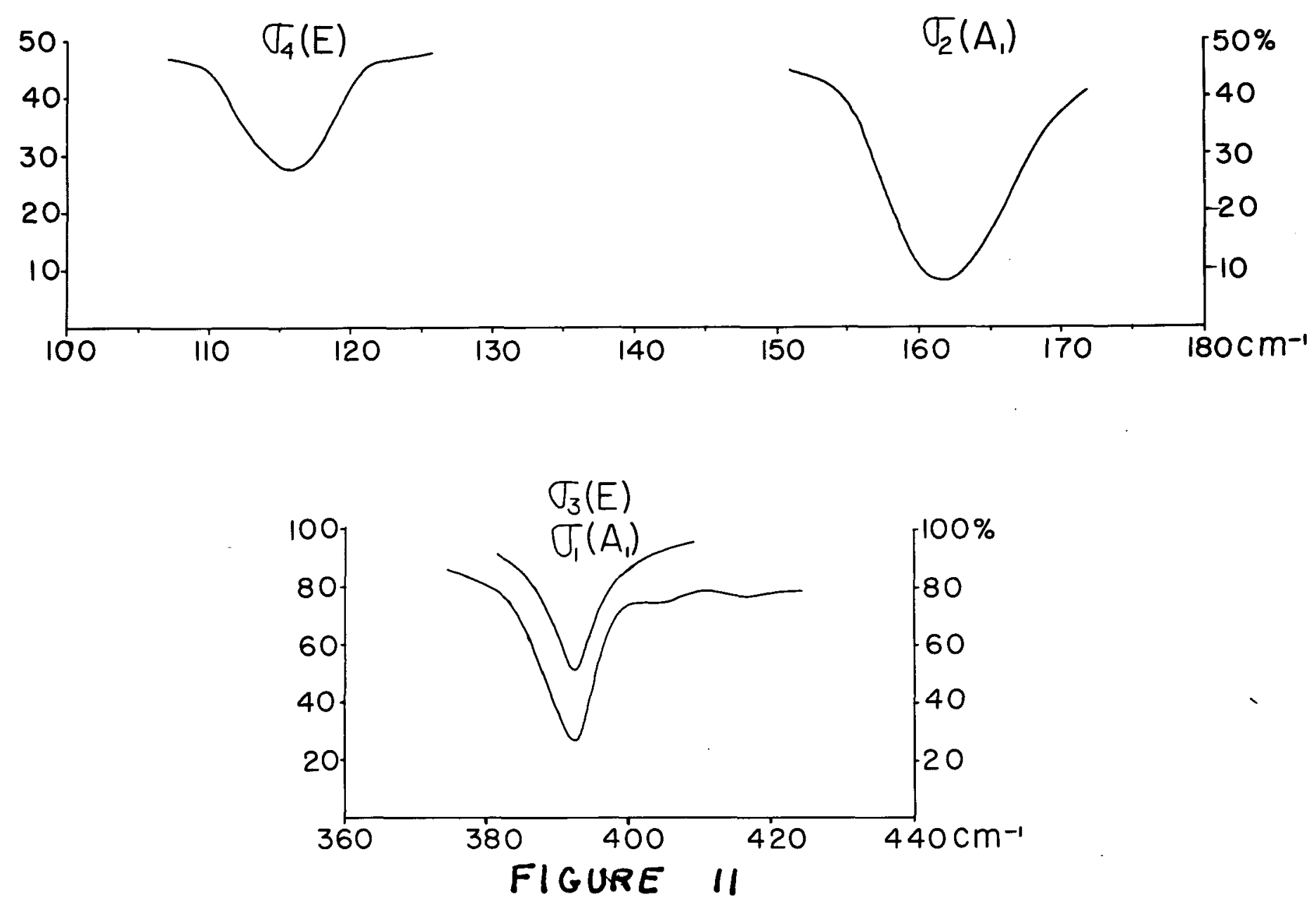

FAR INFRARED SPECTRUM OF $\mathrm{PBr}_{3}$ 
values assumed for $\sigma_{1}$. These turn out to be

$$
\begin{array}{ll}
387 \mathrm{~cm}^{-1} & 24^{\circ} 511 \geqslant \beta \geqslant 65^{\circ} \mathrm{g} 1 \\
397 \mathrm{~cm}^{-1} & 26^{\circ} 091 \geqslant \beta \geqslant 63^{\circ} 51^{\prime}
\end{array}
$$

The angle picked to use was $64^{\circ}$, both because it corresponds to $\sigma_{1}=392 \mathrm{~cm}^{-1}$ and because it bears the same ratio to the electron diffraction data as do the microwave to electron diffraction determinations for $\mathrm{SbCl}_{3}$ and $\mathrm{AsCl}_{3}$. The constants and results for this molecule are summarized below.

TABIE XIII

$$
\begin{array}{rlrl}
\beta & =64^{\circ} & a_{I} & =18.27 \times 10^{4} \mathrm{dynes} / \mathrm{cm} \\
M_{P} & =30.98 \mathrm{amu} & a_{I} & =0.342 \times 10^{4} \mathrm{dynes} / \mathrm{cm} \\
M_{\mathrm{Br}} & =78.93 \mathrm{amu}(50 \%) & \alpha_{1} & =2.398 \times 10^{4} \mathrm{dynes} / \mathrm{cm} \\
M_{B r}^{\prime} & =80.93 \mathrm{amu}(50 \%) & \alpha_{I} & =0.693 \times 10^{4} \mathrm{dynes} / \mathrm{cm} \\
r_{0} & =2.24 \times 10^{-8} \mathrm{~cm}
\end{array}
$$

From the isotope abundance we see that the molecular hybrids will be present in the followins percentages

$$
\begin{array}{ll}
\mathrm{P}^{3} \mathrm{IBr}_{3}^{79} & 12.5 \% \\
\mathrm{P}^{3 I_{\mathrm{Br}}^{79}} \mathrm{Br}^{81} & 37.5 \% \\
\mathrm{P}^{3 I_{\mathrm{Br}}^{79}{ }_{\mathrm{Br}}^{81}} & 37.5 \% \\
\mathrm{P}^{3 I_{\mathrm{Br}}^{81}} & 12.5 \%
\end{array}
$$

The largest shifts w1ll probably be produced by the complete 
bromine substitution and these displacements in frequency can be calculated from the formulae given above; they a re

$$
\begin{aligned}
& \delta \sigma_{1}=-0.90 \mathrm{~cm}^{-1} \\
& \delta \sigma_{2}=-1.88 \mathrm{~cm}^{-1} \\
& \delta \sigma_{3}=-0.40 \mathrm{~cm}^{-1} \\
& \delta \sigma_{4}=-1.57 \mathrm{~cm}^{-1}
\end{aligned}
$$

which a re quite in accordance with Figure Il.

\section{(4) Antimony Trichloride}

This is a solid melting at $73.4^{\circ} \mathrm{C}$ and was prepured for observation by the method described in the experimental section above. The molten SbCl.3 was always dissolved to saturation in the paraffin and tho solid shoets of parafinplus-sbcl.s whose spectrawere measured had ticicknesses of about $1 \mathrm{~mm}$ or slightly more.

The previously obtained Raman frequencies are

$$
\begin{aligned}
& \text { TABIE XIV } \\
& \sigma_{1}=360 \mathrm{~cm}^{-1} \\
& \sigma_{2}=165 \mathrm{~cm}^{-1} \\
& \sigma_{3}=320 \mathrm{~cm}^{-1} \\
& \sigma_{4}=134 \mathrm{~cm}^{-1}
\end{aligned}
$$

and the infrared spectrum obtained is shown in Figure 12 All of these runs were made with paraffin-sample sheets of about $1 \mathrm{~mm}$ except for the extra $\sigma_{1}$ measurement which was 

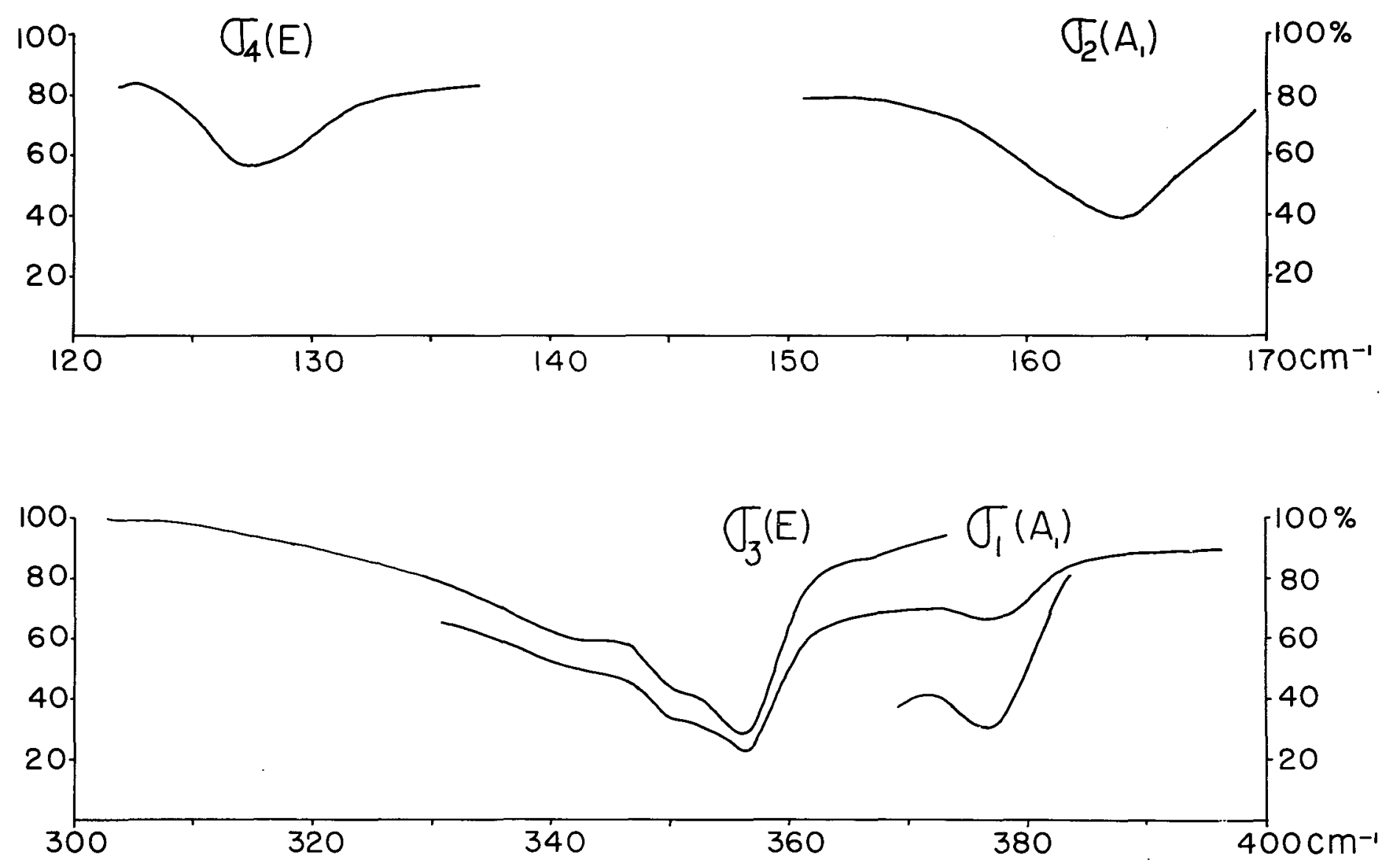

FIGURE IZ

FAR INFRARED SPECTRUM OF $\mathrm{SbCl}_{3}$ 
with a sample of $2.5 \mathrm{~mm}$ thickness. The infrared frequencies and assignments assumed are

$$
\begin{aligned}
& \sigma_{1}=376.5 \pm 0.7 \mathrm{~cm}^{-1} \\
& \sigma_{2}=164.0 \pm 0.5 \mathrm{~cm}^{-1} \\
& \sigma_{3}=356.1 \pm 0.5 \mathrm{~cm}^{-1} \\
& \sigma_{4}=128.1 \pm 0.5 \mathrm{~cm}^{-1}
\end{aligned}
$$

The microwave data give a Cl-Sb-CI angle of $99.5^{\circ}$ and the constants assumed and calculated for this molecule are given in the following table.

TABIE XV

$$
\begin{array}{ll}
\beta=610^{\circ} & a_{1}=20.96 \times 10^{4} \text { aynes } / \mathrm{cm} \\
M_{S b}=120.88 \text { amu }(56 \%) & a_{1}=1.551 \times 10^{4} \text { aynes } / \mathrm{cm} \\
M_{C l}=34.98 \mathrm{amu}(44 \%) & \alpha_{1}=1.64 \times 10^{4} \mathrm{aynes} / \mathrm{cm} \\
M_{\mathrm{C}}=36.98 \mathrm{amu}(75 \%) & \alpha_{1}=0.303 \times 10^{4} \mathrm{ayn \theta} / \mathrm{cm} \\
r_{0}=2.325 \times 10^{-8} \mathrm{~cm} &
\end{array}
$$

These atomic masses will give quite a large number of hybrid moleoules although not all of them will be present to any appreciable extent.

$$
\begin{aligned}
& \mathrm{sb}^{12 I_{\mathrm{Cl}}}: 55 \\
& 5 b^{121} \mathrm{CI}_{2}^{35} \mathrm{Cl}^{37} \\
& \mathrm{Sb}^{1 * 1} \mathrm{CI} 55_{\mathrm{Cl}}^{37} \\
& 23.5 \% \quad \mathrm{Sb}^{123} \mathrm{Cl}_{3}^{35} \\
& 18.5 \% \\
& \mathrm{Sb}^{12 I_{\mathrm{CI}} 37} \\
& 23.5 \% \\
& 5 \mathrm{~b}^{123} \mathrm{CI} \mathrm{Cl}^{35} \mathrm{CI} \\
& 7.8 \% \quad \mathrm{Sb}^{123} \mathrm{CI}{ }^{35} \mathrm{CI} \mathrm{2}^{37} \\
& 18.5 \% \\
& 0.9 \% \quad 5 b^{123} \mathrm{CI}_{3}^{37} \\
& 6.2 \% \\
& 0.7 \%
\end{aligned}
$$

From this it can be seen that the only symmetric substitution of any consequence will be the sblil $\rightarrow$ sbliz change. This produces the relatively negliglble frequency shifts 


$$
\begin{aligned}
& \delta \sigma_{1}=-0.595 \mathrm{~cm}^{-1} \\
& \delta \sigma_{2}=-0.370 \mathrm{~cm}^{-1} \\
& \delta \sigma_{3}=-0.772 \mathrm{~cm}^{-1} \\
& \delta \sigma_{4}=-0.098 \mathrm{~cm}^{-1}
\end{aligned}
$$

However, the substitution of the chlorines produces considerably larger displacements. The principal hybrids are

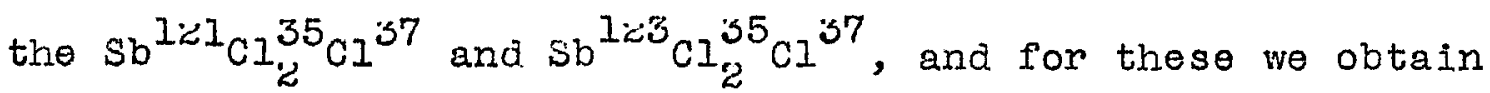

$$
\begin{aligned}
& \frac{\delta \sigma_{1}}{\sigma_{1}}+\frac{\delta \sigma_{2}}{\sigma_{2}}=-0.014 \\
& \frac{\delta \sigma_{3}}{\sigma_{3}}+\frac{\delta \sigma_{y}}{\sigma_{4}}=-0.018 \\
& \frac{\delta \sigma_{5}}{\sigma_{5}}+\frac{\delta \sigma_{6}}{\sigma_{6}}=-0.013
\end{aligned}
$$

values which are satisfied by

$$
\begin{aligned}
& \delta \sigma_{1}=-1.5 \mathrm{~cm}^{-1} \\
& \delta \sigma_{2}=-1.9 \mathrm{~cm}^{-1} \\
& \delta \sigma_{3}=-5.0 \mathrm{~cm}^{-1} \\
& \delta \sigma_{4}=-0.5 \mathrm{~cm}^{-1}
\end{aligned}
$$

and which are, to a certain extent, compatible with the appearance of the $\sigma_{3}$ absorption in Figure 12. It will be noticed that at about $350 \mathrm{~cm}^{-1}$ there is evidence of a secondary absorption. Ihis is aisplaced from the main absorption by about $5.0 \mathrm{~cm}^{-1}$ and so could well be explained on the basis of the indicated frequency shifts. The long sloping absorption on the low frequency side of the $\sigma_{3}$ minimum is similar in form to the $\sigma_{3}$ absorption of $s b B r_{3}$ to be described in the next section. Weither of these seem to be explainable 
In terms of properties of the isolated molecule.

It is interesting to note the size of the shifts for the complete substitution of the chlorines even though the concentration of these is too small to be observable.

$$
\begin{aligned}
& \delta \sigma_{1}=-8.64 \mathrm{~cm}^{-1} \\
& \delta \sigma_{2}=-3.44 \mathrm{~cm}^{-1} \\
& \delta \sigma_{3}=-7.52 \mathrm{~cm}^{-1} \\
& \delta \sigma_{4}=-3.52 \mathrm{~cm}^{-1}
\end{aligned}
$$

\section{(5) Antimony Tribromide}

This substance has not heretofore been observed either by Raman or Infrared methods. The best value for the bond angle is the value $96^{\circ}$ for the Br-sb-Br angle which is quoted by pauline on the basis of electron diffraction measurements. The material was prepared for observation in the same fashion as $\mathrm{SbCl}_{3}$, except that the extra precaution of two dissolutions and recoveries from $C_{2}$ was followed in this case; this represented an attempt to $b \theta t$ as pure a sample as possible because the spectrum shows some puzzling features which were first atiributed to possible impurities.

The spectrum obtained is shown in Figure 13. The two lrwest frequencies are unequivocal enough but the question of how to assign the absorption between $220 \mathrm{~cm}^{-1}$ and $250 \mathrm{~cm}^{-1}$ has not been satisfactorily answered. The broad absorption has a number of separate minima and these 

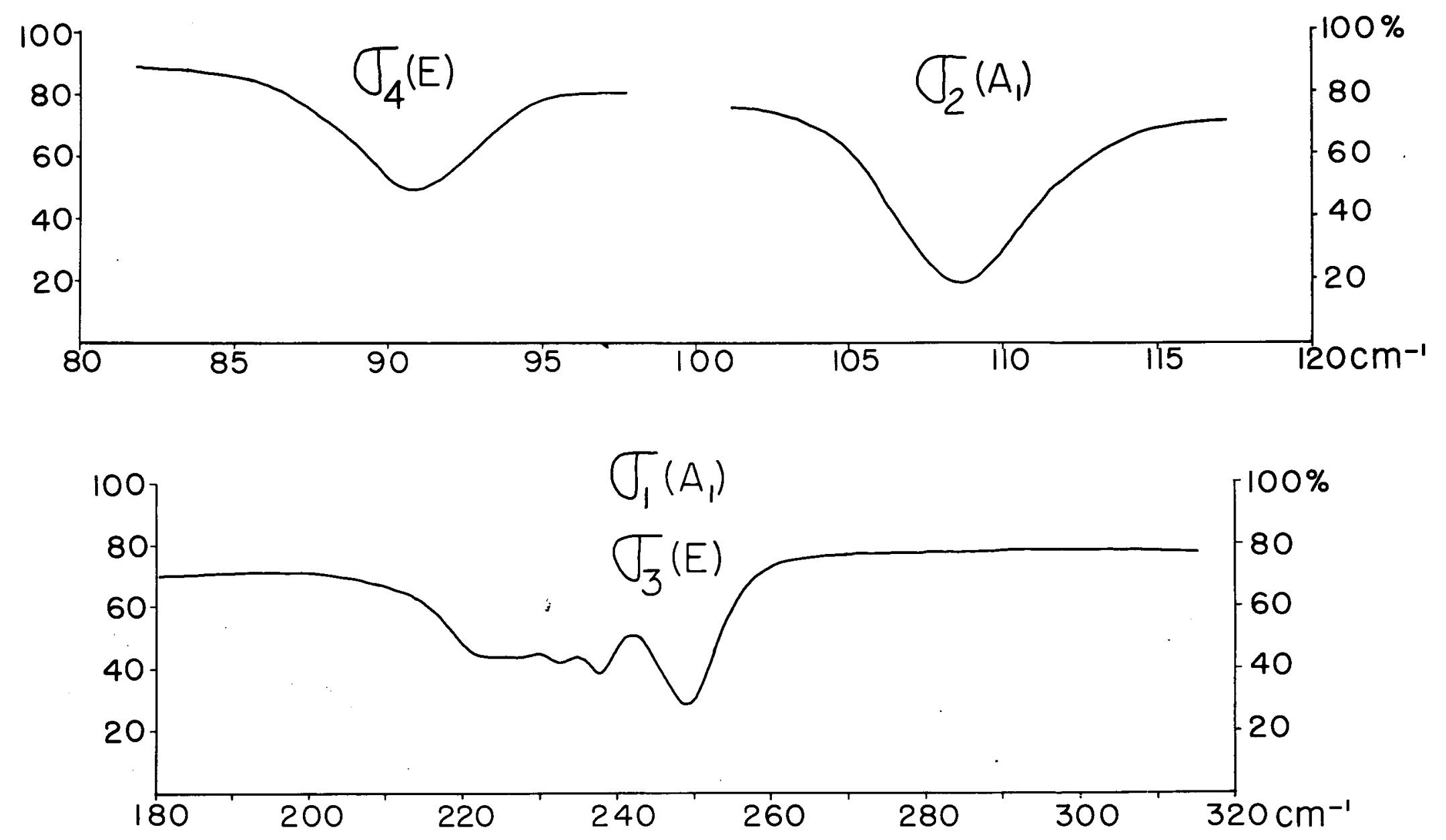

FIGURE I3

FAR INFRARED SPECTRUM OF SbBr 
persist, both ir relative intensity and in position as the concentration of the $\operatorname{sbBr}_{3}$ in the paraffin is changed.

All observed absorption minima are given in the following table.

$$
\begin{aligned}
& \text { TABLA XVI } \\
& \sigma_{1}, \sigma_{3}\left\{\begin{array}{l}
248.4 \mathrm{~cm}^{-1} \\
237.0 \mathrm{~cm}^{-1} \\
231.6 \mathrm{~cm}^{-1} \\
226.0 \mathrm{~cm}^{-1} \\
222.3 \mathrm{~cm}^{-1}
\end{array}\right. \\
& \sigma_{2}=108.5 \pm 0.5 \mathrm{~cm}^{-1} \\
& \sigma_{4}=90.8 \pm 0.5 \mathrm{~cm}^{-1}
\end{aligned}
$$

As can be seen from Figure 13, the $248.4 \mathrm{~cm}^{-1}$ absorption is the most prominent in the broad absorption region.

The initial attompt at an explanation of the very wide absorption band was on the assumption of isotopic frequeney shifts, and, indeed, this molectole shows a greater number of hytrids than any of the others examined. The percentages of isotopes naturally present and the bond angle and $\mathrm{Sb}-\mathrm{Br}$ distance are

$$
\begin{array}{ll}
\beta=62^{\circ} & r_{0}=2.55 \times 10^{-8} \mathrm{~cm} \\
M_{\mathrm{Sb}}=120.88(56 \%) & \mathrm{m}_{\mathrm{Br}}=78.9(50 \%) \\
M_{\mathrm{Sb}}=122.88(44 \%) & \mathrm{m}_{\mathrm{Br}}^{\prime}=80.9(50 \%)
\end{array}
$$

which yield the percentages of molecules shown below: 


$$
\begin{aligned}
& \mathrm{Sb}^{121_{\mathrm{Br}}^{79}} \quad 7.0 \% \quad \mathrm{Sb}^{123} \mathrm{Br}_{3}^{79} \quad 5.5 \% \\
& \mathrm{Sb}^{12 I_{\mathrm{Br}}^{7}}{ }_{\mathrm{Br}}^{81} \quad 21.0 \% \quad \mathrm{Sb}^{123_{\mathrm{Br}}^{79} \mathrm{Br}}{ }^{81} \quad 16.5 \% \\
& \mathrm{Sb}^{12 I_{\mathrm{Br}}{ }^{79_{\mathrm{Br}}^{81}} \quad 21.0 \%} \quad \mathrm{Sb}^{123_{\mathrm{Br}}{ }^{79_{\mathrm{Br}}^{81}}} \quad 16.5 \% \\
& \begin{array}{llll}
\mathrm{Sb}^{12} 1_{\mathrm{BI}_{3}^{81}}^{81} & 7.0 \% & \mathrm{Sb}^{123} \mathrm{Br}_{3}^{81} & 5.5 \%
\end{array}
\end{aligned}
$$

and the calculated sums of frequency shifts are, from the formulae above

$$
\begin{aligned}
& \mathrm{Sb}^{12 I_{\mathrm{Br}}^{79}} \rightarrow \mathrm{Sb}^{12 I_{\mathrm{Br}}^{81}} \\
& \frac{\delta \sigma_{1}}{\sigma_{1}}+\frac{\delta \sigma_{2}}{\sigma_{2}}=-0.017 \\
& \frac{\delta \sigma_{3}}{\sigma_{3}}+\frac{\delta \sigma_{4}}{\sigma_{4}}=-0.019 \\
& \mathrm{Sb}^{12 I_{\mathrm{Br}} 7^{9}} \rightarrow \mathrm{Sb}^{2} 2 \mathrm{I}_{\mathrm{Br}} 7^{9} \mathrm{Br}^{81} \\
& \frac{\delta \sigma_{1}}{\sigma_{1}}+\frac{\delta \sigma_{2}}{\sigma_{2}}=-0.006 \\
& \frac{\delta \sigma_{3}}{\sigma_{3}}+\frac{\delta \sigma_{4}}{\sigma_{4}}=-0.007, \frac{\delta \sigma_{5}}{\sigma_{5}}+\frac{\delta \sigma_{6}}{\sigma_{6}}=-0.005
\end{aligned}
$$

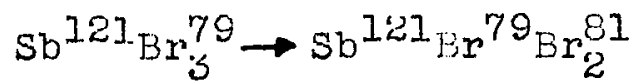

$$
\begin{aligned}
& \frac{\delta \sigma_{1}}{\sigma_{1}}+\frac{\delta \sigma_{2}}{\sigma_{2}}=-0.011 \\
& \frac{\delta \sigma_{3}}{\sigma_{3}}+\frac{\delta \sigma_{4}}{\sigma_{4}}=-0.012, \frac{\delta \sigma_{5}}{\sigma_{5}}+\frac{\delta \sigma_{6}}{\sigma_{6}}=-0.013 \\
& \mathrm{Sb}^{12 \mathrm{I}_{\mathrm{Br}}^{79}} \rightarrow \mathrm{Sb}^{12 \mathrm{~B}^{7}} \mathrm{Br}_{3}^{79} \\
& \frac{\delta \sigma_{1}}{\sigma_{1}}+\frac{\delta \sigma_{2}}{\sigma_{2}}=-0.006 \\
& \frac{\delta \sigma_{3}}{\sigma_{3}}+\frac{\delta \sigma_{4}}{\sigma_{4}}=-0.005
\end{aligned}
$$


using the pauling value of $61^{\circ}$ for the angle - The difference between the sum for two substitutions such as

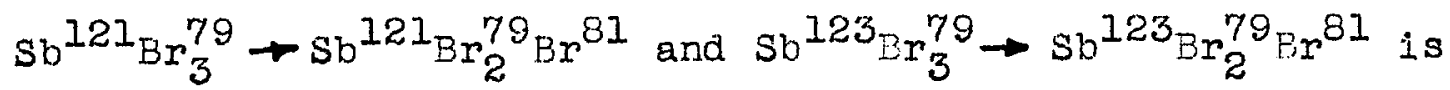
small and need not be considered. The assumption which would seem to come the nearest to explaining the absorption in the $250 \mathrm{~cm}^{-1}$ region would be that it represents the total spread of frequencies between the lowest possible frequency of $\sigma_{3}$ and the highest erequency of $\sigma_{1}$. However, even if three-quarters of the frequency shift for any one species is assumed to occur in the $\sigma_{1}$ and $\sigma_{3}$ vibrations, this allows a frequency range of only $14 \mathrm{~cm}^{-1}$, which would be strongly absorhed. It is true of course that when prepared in this fashion, the substances show bands that are quite broad, but even with this it is hard to ses how the necessary range of so $\mathrm{cm}^{-1}$ can be produced.

Table XVIII gives the constants calculated on the basis of extrerie assumptions regaraing the assignments.

TABLE KVII

Assignments fissumed
(frequencies in $\mathrm{cm}^{-1}$ )

$$
\text { (frequencies in } \mathrm{cm}^{-1} \text { ) }
$$$$
\left(\mathrm{cm}^{-1}\right)\left(\mathrm{cm}^{-1}\right) \quad\left(\mathrm{cm}^{-1}\right)
$$

$248.4 \quad 108.5 \quad 243.4$

$22 \% .3 \quad 108.5 \quad 22 \% .3$ $248.4 \quad 108.5$ $222.3 \quad 108.5$ $237.0 \quad 108.5$ $248.4 \quad 108.5$ $22 \% \cdot 3$ 248.4 248.4 237.0
Force constants $\times 10^{-4}$ (aynes/cm)

$\begin{array}{lrrrr}\left(\mathrm{cm}^{-1}\right) & \boldsymbol{a}_{\mathbf{1}} & \mathbf{a}_{\mathbf{1}} & \boldsymbol{\alpha}_{\mathbf{1}} & \boldsymbol{\alpha}_{\mathbf{1}}^{*} \\ 90.8 & 16.86 & 0.33 & 1.53 & 0.10 \\ 90.8 & 13.38 & 0.54 & 1.55 & 0.11 \\ 90.8 & 14.75 & 1.39 & 1.54 & 0.10 \\ 90.8 & 15.51 & -0.52 & 1.54 & 0.11 \\ 90.8 & 16.25 & 0.22 & 1.53 & 0.11 \\ 90.8 & 15.87 & 1.32 & 1.53 & 0.11\end{array}$


The last two make use of a $257 \mathrm{~cm}^{-1}$ minimum which appears in ligure 13 as the smaller absorption, just to the lower frequency side of the main $248 \mathrm{~cm}^{-1}$ absorption. 


\section{SUMLARY AND CONCLUS IONS}

The spectra of five pyramidal trihalides were obtained and, except for $\mathrm{SbBr}_{3}$, the four fundamental frequencies were located with reasonable accuracy. Using a four constant harmonic potential function devised by Howard and Wilson f'orce constants were cajculated on the basis of the observed frequencies. In Table XVIII the force constants thus calculated are given, aidon with the bond angles ass umed in making the calculations. The extreme values possible for $\mathrm{SbBr}_{3}$ are given.

\section{TABIE XVIII}

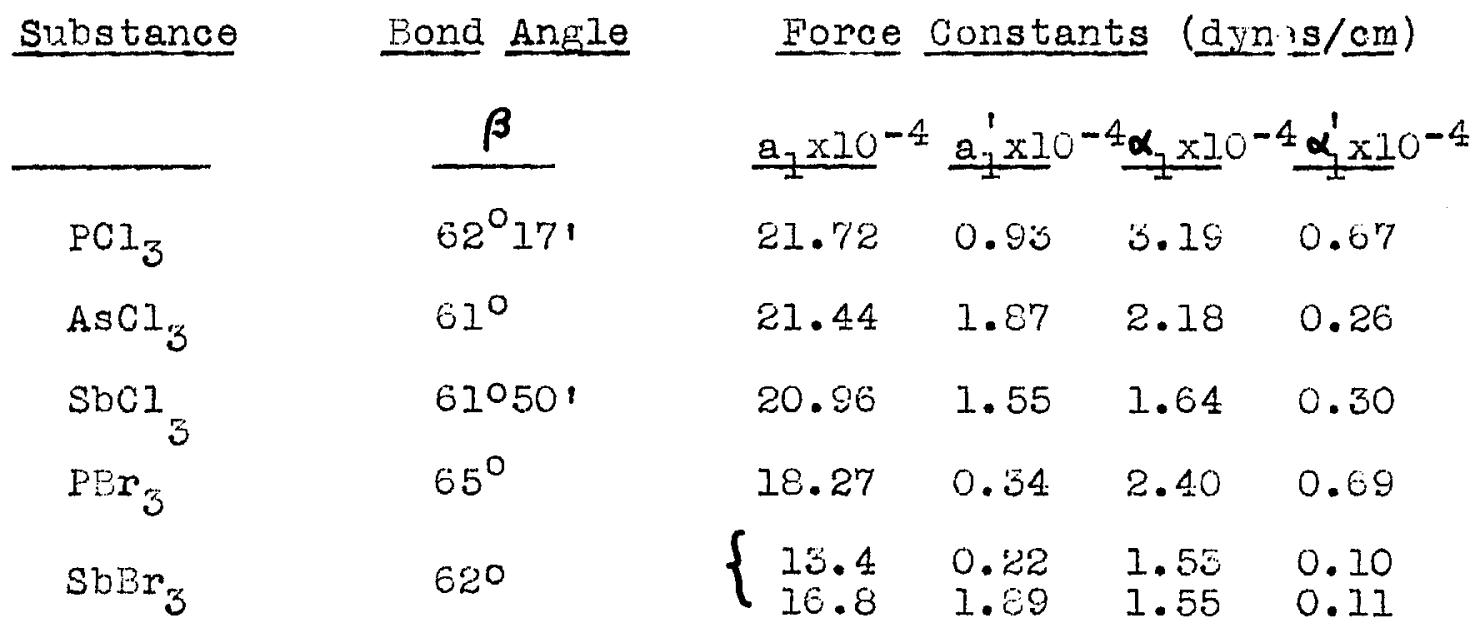

The questions of anharmonicities and vibration-rotation interactions cannot be answered on the basis of data obtained from molecules in a condensed state. The frequency shifts resulting from anharmonicity would be very small. For a molecule such as vater these shifts are all le ss than 
five percent and in $\mathrm{FCl}_{3}$ we deal with atoms of much greater mass and force constants of a third of the magnitude. I'his means that the oscillations will be of rather small amplitude and hence, that the effect of the anharmonic constants will not be important.

Rotation-vibration interactions could not, in our present stage of instrumentation, be stidied even if the spectra were obtained with the substances in the gaseous phase. The most favorable of the molecules, $\mathrm{PCl}_{3}$, has a $\mathrm{B}$ value of $0.088 \mathrm{~cm}^{-1}(44)$, which means that the spacing of the rotational lines would be $0.716 \mathrm{~cm}^{-1}$, which is too small for resolution with the spectrograph. The band envelopes could be measured and for $\mathrm{PCI}_{S}$, since the $\mathrm{P}$ and $\mathrm{R}$ Branch naxima would be sepirated by $12 \mathrm{~cm}^{-1}$.

The most valuable result of getting the far inirared spectrum of these abstances in the gaseous phase would be the determination of the effect of condensation on the vibrational frequencies. Mielsen and Ward (43) attempted a study of the frequency shifts accompanying change of

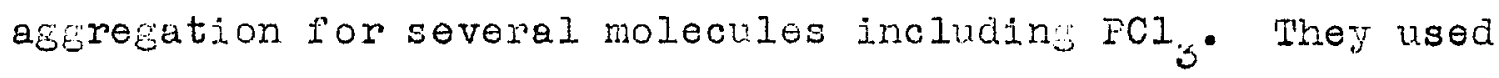
Raman techniques to make this investigation, kowever, and it shoula be possible to improve considerably on their accuracy with the infraredinstrument now at our disposal. Towever,

(43) J. Mielsen and Ward, J. Chem. Phys. 10, 81 (1942)

(44) Gordy, Smith, and Trambarulo, op. cit. 
in order to carry out this measurement some improvements in cell design will have to be worked out. During the course of the present investigation, two attempts were made at measuring faseous $\mathrm{PCl}_{3}$, it belng the only one of these substances having a high enough vapor pressure to be used with the cell lengths now available to us. In the first case the cell window was polyethylene and in the second case Teflon. In both instances it was found that the plastios absorbed the trihalide to such an extent that, after exhausting the cell of the $\mathrm{PCl}_{3}$ vapor, the "empty cell" gave the same spectrum as it had witin $20 \mathrm{~cm}$ pressure of tho vapor present. The solution to this is to have a multiple path cell (so that low pressure vapors covld be mu) with windows of crystal quartz. In order to keep the window size as small as possible, the windows would have to be placed near the entrance slit of the spectrometer.

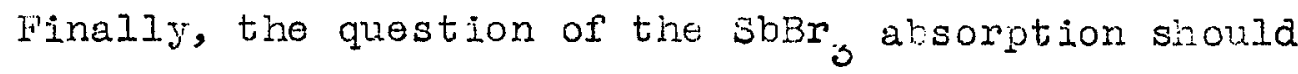
be further investigatod. Tre author attemptea to find a non-polar solvent for sbCl, sbEr, and $\mathrm{BiCl}_{j}$, with no success w hatever. However, a possible approach would be to evaporate a thin layer of sbEr onto a sheot of polyethyIene and obtain the spectrum of the solid. This would indicate immediately whether the appearance of tre band is due to the SbErg actually beine in the solid state when the parafin solution technique is used. 


\section{BIBLIOGRAPHY}

Bell, E. E., R. A. Oetjen, W. I. Haynie, W. M. Ward, R. L. Hansler, and H. E. Schauwecher, J. O. S. A. 42,559 (1952)

Benedjct, W. S., private communication, 1950.

Brockway, I. 0., Rev. Mod. Physics, 8, 20I (1936)

Burnelie, I., J. Chem. Phys. 18, 1300 (1950)

Dennison, D. M., Fhilosophical Magazine, 1, 195 (1926)

- E. H. Randall, Nathan Ginsburg and Louis R. Weber, Phys. Rev. 5i, 160 (1937)

Eyring, H., J. Walter, and G. Kimball, Quantum Chemistry, John Wiley and Sons, Inc., New York, 1944.

Gordy, W., W. Smith and P. Trambarulo, Microwave Spectroscopy, John Wley and Sons, Inc., Tew York, 1953.

Gutowsky, H., J. Chem. Phys., 20, 1652 (1952)

FerzberE, G., Holecular spectra and ilolecular Etructure II Infrared and Raman Spectra of Polyatomic Molecules, D. Van iTostrand Co., ITew Yorkx, 1945.

Howerd, J., and E. Wilson, J. Chem. Phys., 2, 630 (1934)

KohIrausch, K. W. F., Der Smekal-Raman-Effekt, Ergänzungsband, 1951-1937, Julius Springer Verlag, Berlin, 1958.

Lechner, F, Wiener Ber., 141, 600 (195\%)

Margenau, H., and G. Murphy, The Hathematics of Physics and Chemistry, D. Van Wostrand Co., New York, 1940.

Nielsen, J., and - Wara, Z. Chom. Phys., 10, 81 (194\%)

O'Loane, J., J. Chem. Phys., 21, 669 (1953)

Pauling, I., The Nature of the Chemical Bond, Cornell University Fress., 1941 .

Rosenthal, J., Phys. Rev., 47, 235 (1955)

, and E. Salant, Fhys. Rev., 4z, 81z (1932) 


\section{BIELIOGRAPEY (CONTIINED)}

Shaffer, W. H., J. Chem. Phys., 9, 607 (1941)

, mimeographed notes, The Ohio State University, 1948.

Wilson, M. K., J. Chem. Phys., 20, 1716 (1952)

Wu, T. Y., Vibration Spectra and structure of Polyatomic inolecules, National iniversity of Peking, Kun-Ming, China, 1939 .

Iandbook of Chemistry and Physics, Chemical Kubher PubIishine Company, Cleveland, Chio, 1949.

International Critical Tables, HoGraw-Hill Book Company, New York, 1926. 


\section{AUTOBIOGRAPHY}

I, Philip W. Davis, was born in St. Louis, Missouri on June 19, 1925. Very shortly thereafter the family moved to Columbus, Ohio, where I have lived (with minor interruptions) ever since. My secondary education was received from the Ohio State University IIigh School and upon graduation I entered the Army of the United States. I was discharged in 1946. I then enrolled in the ohio State University and was graduated with a Bachelor of Science degree with majors in physics and mathematics in December, 1948. The following september I entered the Graduate School of The Oh10 State University. In the fall of 1950 I was appointed a Research Associate, a position which I have held since then with the exception of the year 195\%-53, when I was a University Fellow. 